\title{
Water-based flame retardant coating using nano-boehmite for expanded polystyrene (EPS) foam
}

\author{
S. Hamdani-Devarennes ${ }^{\mathrm{a}, \mathrm{b}}$, R. El Hage ${ }^{\mathrm{a}, \mathrm{c}}$, L. Dumazert ${ }^{\mathrm{a}}$, R. Sonnier ${ }^{\mathrm{a}, *}$, L. Ferry ${ }^{\mathrm{a}}$, \\ J.-M. Lopez-Cuesta ${ }^{\mathrm{a}}$, C. Bert ${ }^{\mathrm{d}}$ \\ a C2MA, Ecole des Mines d'Ales, 6, avenue de Clavieres, 30100 Ales, France \\ ${ }^{\mathrm{b}}$ Fluid System Group, Saint Gobain Recherche, 39 quai Lucien Lefranc. BP 135, 93303 Aubervilliers CEDEX, France

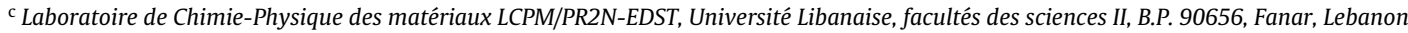 \\ ' Saint Gobain CREE (Centre de Recherches et d'Etudes Européen), 550 av. Alphonse Jauffret BP 224, 84306 Cavaillon CEDEX, France
}

\section{A B S T R A C T}

Expanded polystyrene (EPS) foam has been successfully flame retarded by a water-based coating containing nanoparticles of boehmite and poly(vinyl alcohol) (PVOH) as char former. Boehmite enhances the charring of $\mathrm{PVOH}$. The influence of suspension viscosity, coatings number, impregnation time and drying method was studied to monitor the amount of coating deposited and the coating thickness. The coating suspension is able to penetrate into the core of the foam. EPS without hexabromocyclododecane (HBCD) is upgraded from F to E rating according to the NF EN ISO 11925-2 standard when the penetration of coating suspension into the core is high enough, due to the formation of a char layer reinforced by nano-boehmites even if EPS does not shrink away from the flame.

Keywords:

Flame retardancy

Fire-proof coating

Boehmite

Expanded polystyrene

\section{Introduction}

Since the beginning of the twentieth century, synthetic polymers have become increasingly important materials in industry. As plastic processing technologies, the addition of a blowing agent became a natural extension of polymer processing. Presently, foam extrusion, injection molding, molded bead, $x$-linked foam, reactive foaming, and gelation are well-known methods of making polymeric foams, and polymeric foams have become a well-developed branch in the polymer industry. The most successful polymeric foam is probably expanded polystyrene (EPS) due to its numerous useful advantages, such as good cushioning properties, acoustical and thermal insulation, ease of processing, low cost and light weight [1]. Nevertheless EPS presents serious fire hazards and needs to be flame-retarded [2].

Expanded polystyrene is typically made by suspension polymerization of a mixture of styrene monomer(s) and flame retardant in water to form beads of styrenic polymer. The small beads (e.g., averaging about $1 \mathrm{~mm}$ in diameter) are pre-expanded with steam and

\footnotetext{
* Corresponding author.

E-mail address: rodolphe.sonnier@mines-ales.fr (R. Sonnier).
}

molded again with steam to produce large blocks (e.g., up to several meters high and 2-3 $\mathrm{m}$ wide) that are cut in the desired dimensions. Flame retardants for expanded polystyrene foams have many requirements including thermal stability, substantial solubility in styrene, and high flame retardancy. Hexabromocyclododecane (HBCD) is widely used in thermoplastic polymer compositions to impart flame retardant properties to the compositions. EPS foams fire retarded with typically low levels of $\operatorname{HBCD}(0.5-1 \mathrm{wt} \%)$ [3], provide adequate time for occupants to escape in the event of fire and contribute to protect human lives and property from fire.

Currently, HBCD is the most popular flame retardant in EPS. Nevertheless, some halogenated flame retardant chemicals are now recognized as global contaminants and are associated with adverse health effects in animals and humans, including endocrine and thyroid disruption, immune-toxicity, reproductive toxicity, cancer, and adverse effects on fetal and child development and neurologic function [4-6]. Therefore, the application of halogenated flame retardant has been strictly regulated, or even banned in some countries. In February 2011, the European Union announced that HBCD, the brominated flame retardant used in polystyrene building insulation, will be banned. The REACH (Registration, Evaluation, Authorization and Restriction of Chemicals) identified HBCD as being persistent in the environment, bioaccumulative in biologi- 
cal systems, and toxic. HBCD has been moved from the "candidate list" of chemicals under review. The ban of HBCD took effect effective on August 21, 2015 and is implemented through the European Union's REACH program [7].

Due to this problematic, the research on a new alternative for environmentally friendly flame retardant to replace HBCD becomes an urgent and a great interest for academics and industries.

Besides HBCD, other halogenated [8,9] or halogen-free [10-13] flame retardant systems have been used. Nevertheless, halogenfree flame retardants generally need to be used in larger amounts to be effective. The incorporation of such large amounts of additives in foam can prevent the foam processing. Therefore, flame retardant coating appears as an ideal method to reduce the flammability of EPS foam. Several teams have developed such coatings [14-17].

To the best of our knowledge, all these coatings contain halogenated compounds. Then there is still a need to propose a more environmentally friendly flame retardant coating. Poly(vinyl alcohol) $(\mathrm{PVOH})$ considered as environmentally friendly is a good choice for polymer coating due to its good adhesion property with substrate, no need solvent in coating process, and its charring behavior during burning. As other metal hydroxides, boehmite and pseudo-boehmite have already used to impart flame retardancy in a couple of polymers: ethylene-vinyl acetate copolymer $[18,19]$, polycarbonate/acrylonitrile butadiene-styrene blend [20], poly(methyl methacrylate) [21], polyethylene [22], polyamide 6 [22], polyamide 11 [23], polyester [24,25], polyethersulfone [26] or $\mathrm{PVOH}$ [27]. As both boehmite and PVOH are hydrophilic, boehmite can be incorporated into PVOH without pretreatment, only by simply dispersing the two components in water. The dispersibility of boehmite in water is an advantage to obtain the water-based flame retardant coating in a water soluble polymer. It has already been proved that pseudo-boehmite nanoparticles disperse very well in PVOH and improve significantly its flame retardancy: limiting oxygen index increases from 19.5 for pure PVOH to 30 for PVOH filled with $37.5 \mathrm{wt} \%$ of pseudo-boehmite nanoparticles. Moreover these nanoparticles enhance charring of $\mathrm{PVOH}$ [27]. This article describes the results of a collaborative work concerning the development of a flame retardant coating for EPS foams and leading to three patents [28-30]. The efficiency of the coating to improve the flame retardancy of EPS foams is assessed according to the NF EN ISO 11925-2 standard which is generally required for many applications of EPS foams. Two EPS foams (with and without HBCD) are used to identify the possible synergism or antagonism between the developed coating and HBCD whose modes-of-action are different.

\section{Materials and methods}

\subsection{Materials}

Precipitated boehmite mineral filler under commercial name of CAM was supplied by Saint Gobain Ceramic Materials. It has ellipsoid particle shape, a specific surface area (BET) of $149 \mathrm{~m}^{2} / \mathrm{g}$, pores

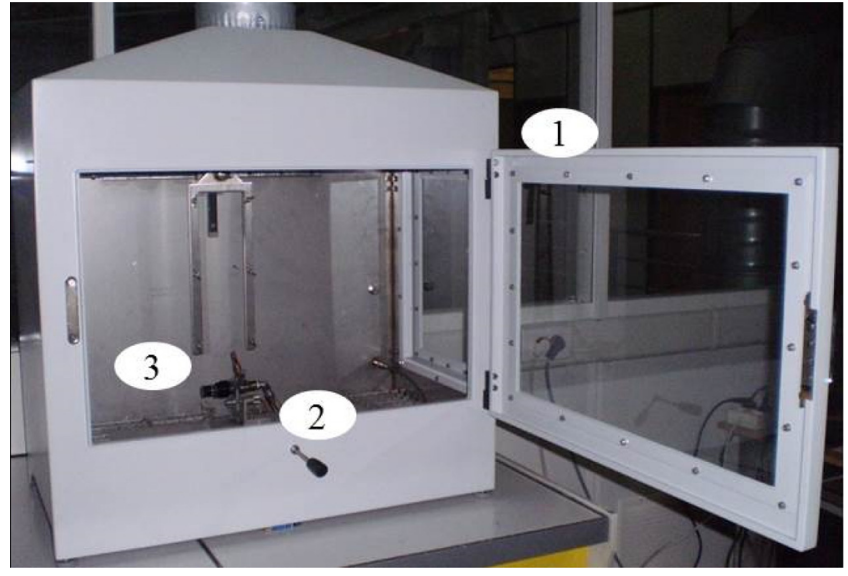

Fig. 1. Standardized single flame source fire test apparatus NF EN ISO 11925-2 and their main components.

volume and mean pore size of $0.43 \mathrm{~cm}^{3} / \mathrm{g}$ and $11.5 \mathrm{~nm}$ respectively (data from manufacturer).

The partially hydrolyzed polyvinyl alcohol (PVOH) was purchased from SEKISUI and used without any purification. Its degree of hydrolysis is $87-89 \mathrm{~mol} \%$, with viscosity of $24.5-27.5 \mathrm{cPs}$, and $\mathrm{pH}$ of about 5-7.

Two types of EPS were used as substrate of coating, EPS without $\mathrm{HBCD}$ with apparent density of $14.16 \pm 0.33 \mathrm{~kg} / \mathrm{m}^{3}$, and EPS-HBCD with apparent density of $16.17 \pm 0.51 \mathrm{~kg} / \mathrm{m}^{3}$. For dip coating in aqueous coating dispersion, EPS blocks were sized according to the required dimensions for fire tests: $250 \times 90 \times 60 \mathrm{~mm}^{3}$.

\subsection{Processing methods}

\subsubsection{Preparation of aqueous coating dispersion}

Dried filler was pulverized in a pulverizator during $10 \mathrm{~s}$ at $6000 \mathrm{rpm}$. The pulverized filler was then dispersed in de-ionized water under mechanical mixing during $4 \mathrm{~h}$. The $16 \mathrm{wt} \%$ of aqueous $\mathrm{PVOH}$ solution was prepared by dissolving the polymer in de-ionized water at around $80^{\circ} \mathrm{C}$ for $4 \mathrm{~h}$ under mechanical mixing, until a homogeneous solution was formed. After cooling to room temperature, $1000 \mathrm{~g}$ of the coating suspension was prepared by mixing $625 \mathrm{~g}$ of $18 \mathrm{wt} \%$ of filler aqueous dispersion with $375 \mathrm{~g}$ of $16 \mathrm{wt} \%$ of PVOH solution. The whole solution was stirred vigorously until a homogenous dispersion was obtained. Consequently, the filler/polymer weight ratio in dried film is fixed to 65/35. To obtain the dried film (studied in Section 3.1), $5 \mathrm{~g}$ of aqueous coating dispersion was dried in a petri dish.

\subsubsection{Static dip coating method of EPS block}

The dip coating process was applied on the EPS-HBCD samples as required for preliminary assessment of their fire behavior. The first step consists in a 5 min manual dipping system in coating solu- (a)

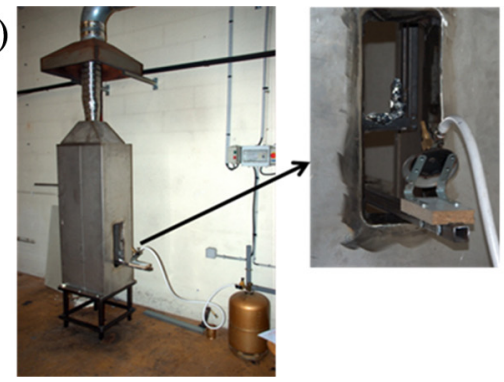

(b)

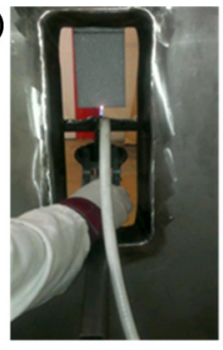

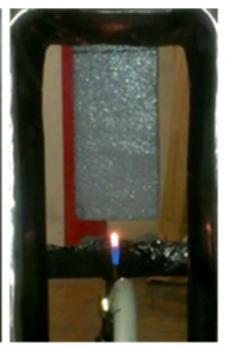

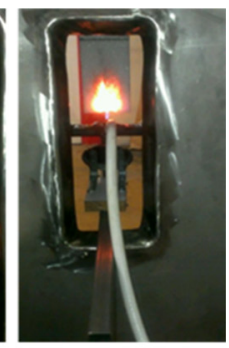

Fig. 2. Simulated single flame source fire test NF EN ISO 11925-2 apparatus (a) and (b) burning process. 


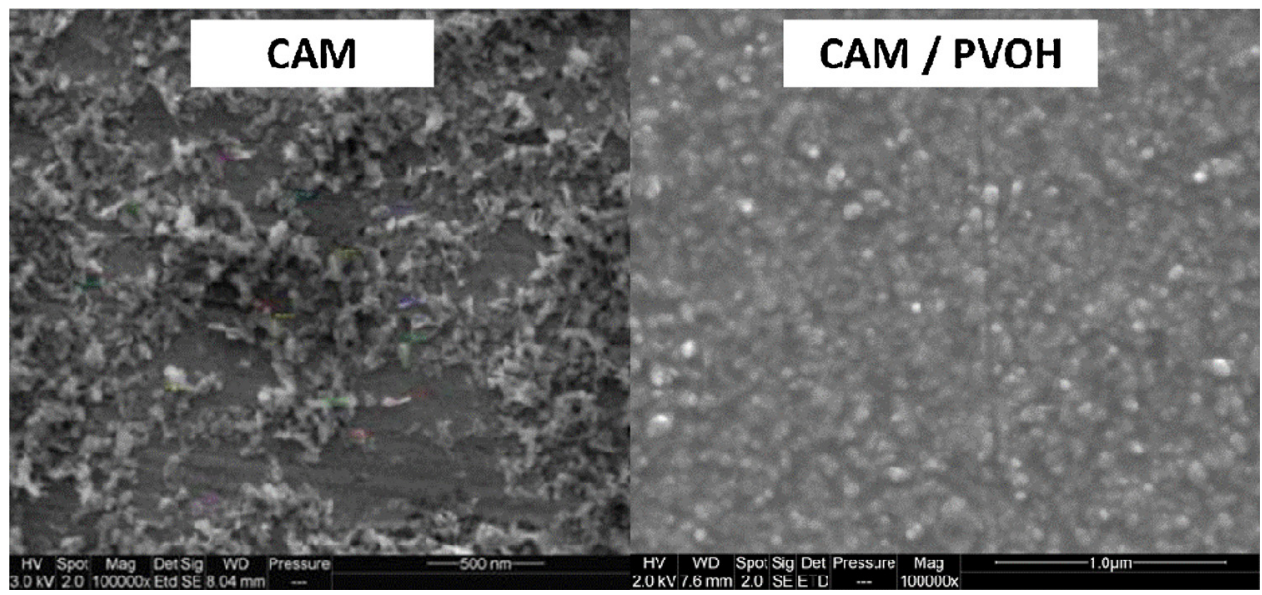

Fig. 3. SEM images of filler CAM (scale bar $500 \mathrm{~nm}$ ) and dried film microstructure (scale bar $1 \mu \mathrm{m}$ ).

tion. Then samples were taken out from the coating suspension and partially dried for $2 \mathrm{~h}$ on a drying rack before application of a second coating layer. Coated blocks were then dried at room temperature until weight stabilization. This step could be repeated several times to increase coating film thickness.

\subsubsection{Optimization of (multi-layer) coating dispersion}

parameters on EPS blocks (Sections 3.2 and 3.3)

$12 \mathrm{wt} \%$ aqueous PVOH solution was prepared by dissolving the polymer in de-ionized water at $\sim 80^{\circ} \mathrm{C}$ for $4-6 \mathrm{~h}$ with stirring until a homogeneous solution was formed. After cooling to room temperature, $10000 \mathrm{~g}$ of a coating suspension was prepared by mixing $6000 \mathrm{~g}$ of $12 \mathrm{wt} \%$ aqueous PVOH solution with $1335 \mathrm{~g}$ of CAM and $2665 \mathrm{~g}$ of water. The whole solution was stirred vigorously until it is well dispersed. The total solid content $(\mathrm{CAM}+\mathrm{PVOH})$ was about $20-21 \mathrm{wt} \%$. The filler/polymer weight ratio in dried film was fixed to $65 / 35$.

The dip coating process was applied on $250 \mathrm{~mm} \times 180 \mathrm{~mm} \times 60 \mathrm{~mm}$ EPS samples as required by the single flame source test "ISO 11925-2" for materials which melt and shrink away from the flame.

\subsubsection{Rotary dip coating on EPS blocks}

In order to improve coating process, a three-step "rotary" dip coating process was used and applied on EPS with and without $\mathrm{HBCD}$. The first step consists in a 5 min manual dipping system in coating suspension to obtain a PVOH/CAM wet layer. Then samples were taken out from the coating suspension and partially dried for $1 \mathrm{~h}$ with a rotational apparatus (rotation speed: $165 \mathrm{rpm}$ ) for better film homogeneity. These steps could be repeated several times to increase coating film thickness. The coating process was completed by a film drying at room temperature by hanging the EPS blocks on a drying rack for several days. Later on, the EPS blocks were dried in oven at $40^{\circ} \mathrm{C}$ during 3 days to guarantee the weight stabilization of EPS blocks.

\subsection{Characterizations}

The size of CAM nanoparticles was determined as hydrodynamic diameter $\left(Z_{\text {average }}\right)$ by measuring the changes in the intensity of light scattered from a suspension of fillers using a zeta sizer Nano ZS from Malvern. About $50 \mathrm{~mL}$ of aqueous filler dispersion was diluted $100 x$ by de-ionized water under magnetic stirring.

The observation of nanoparticles shape, the real filler particle size, filler distribution in PVOH, and coating deposition on EPS were carried out using a FEI Quanta 200 FEG environmental scanning

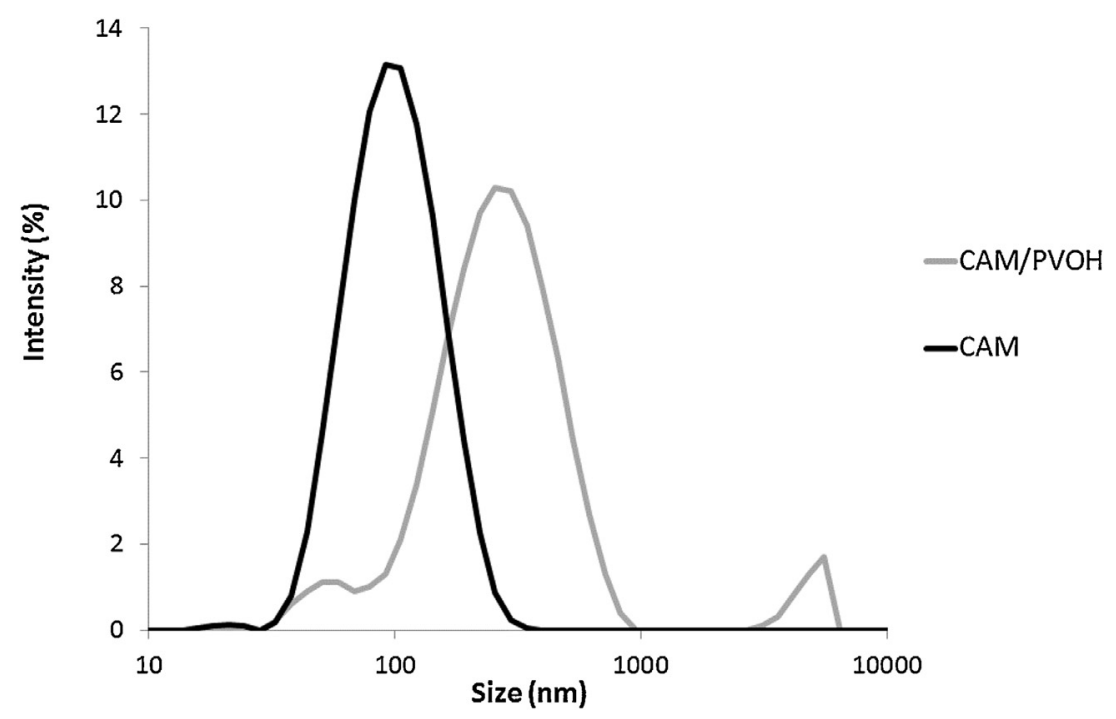

Fig. 4. The evolution of hydrodynamic diameters of CAM in water and in aqueous dispersion of PVOH. 


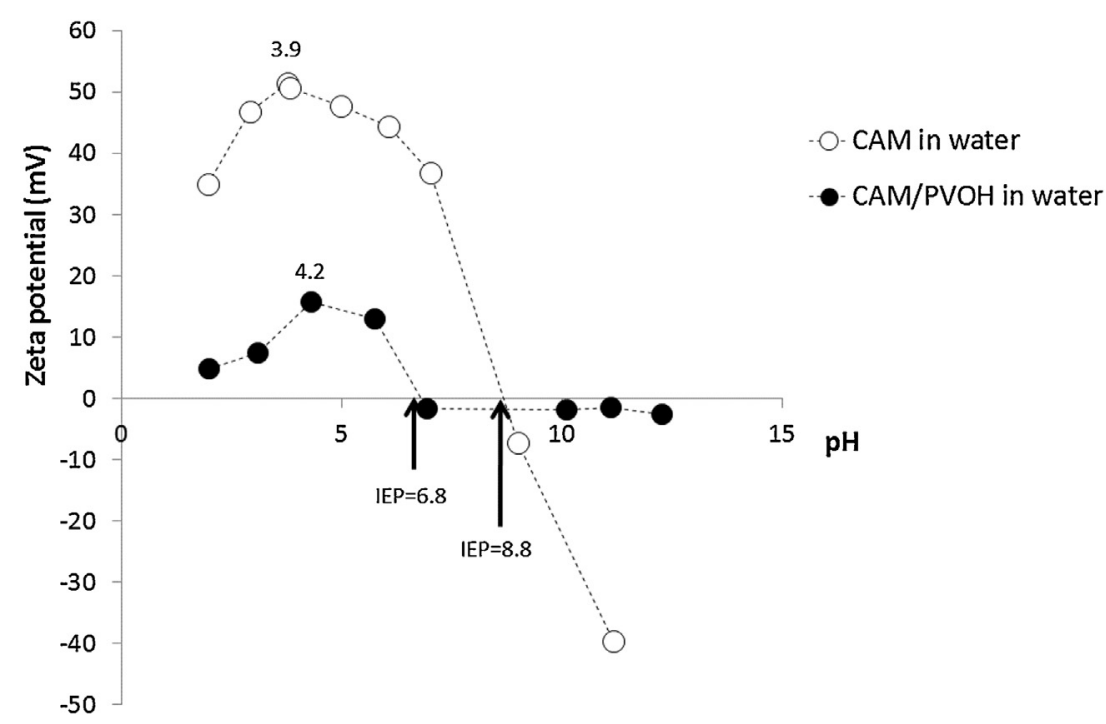

Fig. 5. Influence of $\mathrm{pH}$ on the zeta potential of aqueous suspension of CAM and CAM/PVOH.

electron microscope (ESEM) using an acceleration voltage of $15 \mathrm{kV}$. The filler was dispersed in water after sonication in an ultrasonic bath during $15 \mathrm{~min}$, and then deposited on the copper plate and dried. The SEM images observation was carried out on this dried sample.

The $\mathrm{pH}$ of filler or coating suspension was measured using a $\mathrm{pH}$ meter after their dilution to $10 \times$ in de-ionized water. The $\mathrm{pH}$ measurement was repeated 3 times and averaged.

The viscosity of the PVOH/CAM coating suspension was evaluated using a TA Instruments AR-2000 N cone/plate rheometer: $\left(40 \mathrm{~mm} 2^{\circ}\right.$ steel cone with Peltier plate). All measurements were carried out at $25^{\circ} \mathrm{C}$ under a constant shear stress of $10 \mathrm{~Pa}$ s.

The zeta potential was measured using a Zetasizer Nano ZS from Malvern in order to investigate the effect of $\mathrm{pH}$ on CAM dispersion in water with and without PVOH. The CAM concentration in water without PVOH was about $0.5 \mathrm{wt} \%$. The CAM/PVOH (65/35) concentration after dilution in water was about $0.325 \mathrm{wt} \%$. Suspension $\mathrm{pH}$ was adjusted by adding either $1 \mathrm{M} \mathrm{HCl}$ or $1 \mathrm{M} \mathrm{NaOH}$. The range of $\mathrm{pH}$ studied was $2-12$, as measured by a digital $\mathrm{pH}$ meter.

The thermal stability was investigated by thermogravimetry (TGA) using a Perkin-Elmer TGA-Pyris Manager 6. All measure- ments were performed at least three times for $10 \pm 2 \mathrm{mg}$ sample under nitrogen with a heating rate of $10^{\circ} \mathrm{C} / \mathrm{min}$. The standard deviation for the TGA results was on average $\pm 0.5 \mathrm{wt} \%$.

A simple fire test was developed to provide a first assessment of coating efficiency to improve the flame retardancy of EPS (see supporting information).

Single flame source fire test NF EN ISO 11925-2 on the coated EPS blocks

The Single Flame Source Test NF EN ISO 11925-2 is a method for determining the ignitability by direct small flame impingement of building products used in the vertical orientation and aims to assess their behavior during and after a direct exposure to a flame. $250 \mathrm{~mm} \times 90 \mathrm{~mm} \times 60 \mathrm{~mm}$ EPS blocks with and without HBCD before and after coatings were subjected to this fire test. As prescribed in the standard, propane was used as combustion gas and the air flow rate in the combustion chamber was about $0.6-0.8 \mathrm{~m} / \mathrm{s}$.

During the test, the following information must be recorded:

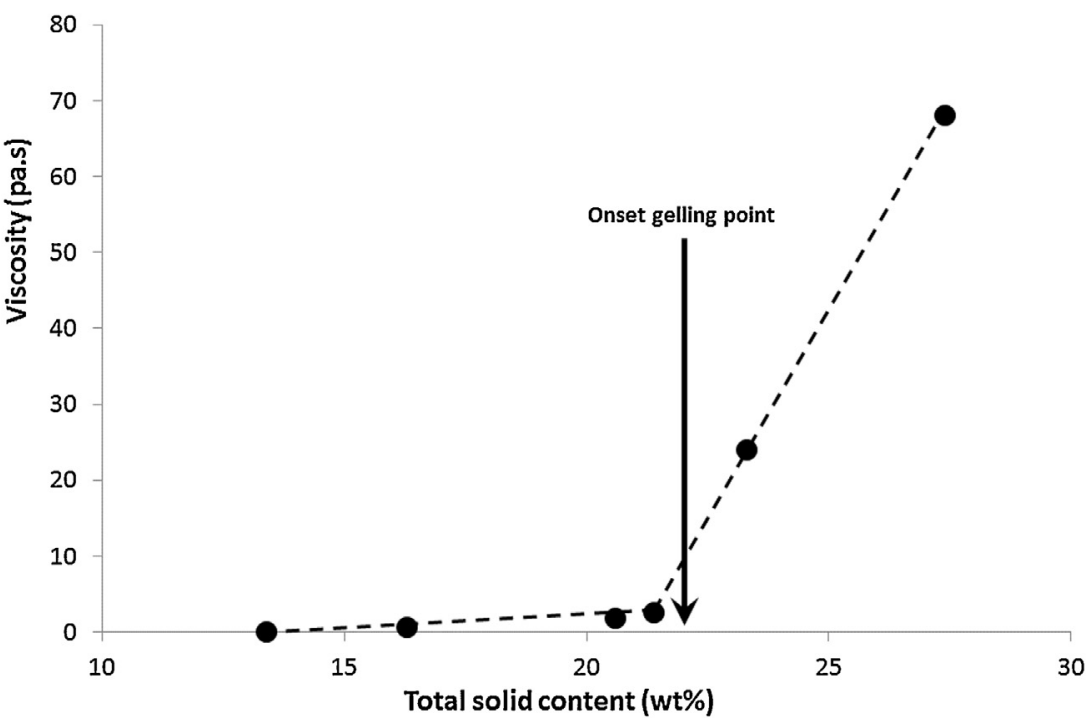

Fig. 6. Relation between PVOH/CAM (35/65) total solid content and viscosity. 
- Ignition time of the product $\left(\mathrm{T}_{\text {ign }} \mathrm{S}\right)$;

- Flame spread:

- If the flame tip reaches $150 \mathrm{~mm}$ above the flame application point, then the time $\left(\mathrm{T}_{\mathrm{m}} \mathrm{s}\right)$ at which it occurs is recorded;

- If the flame tip does not reach $150 \mathrm{~mm}$ above the flame application point, then the distance $\left(\mathrm{F}_{\mathrm{s}} \mathrm{mm}\right)$ covered by the flame is recorded.

- Self-extinguishing time $\left(\mathrm{T}_{\text {self }} \mathrm{S}\right)$

- Ignition of the paper filter located under the EPS block due to dripping $\left(\mathrm{T}_{\text {drip }} \mathrm{s}\right)$

- Observations of physical behavior of the specimen.

Euroclass rating can be summarized as follow:

- Class $\mathrm{E}$ if $\mathrm{F}_{\mathrm{s}}$ is less than $150 \mathrm{~mm}$ after $20 \mathrm{~s}$.

- Class E-d2 if $F_{s}$ is less than $150 \mathrm{~mm}$ after $20 \mathrm{~s}$ and paper filter is ignited.

- Class $\mathrm{F}$ if $\mathrm{F}_{\mathrm{S}}$ is higher than $150 \mathrm{~mm}$

For each formulation a set of six to eight specimens was tested using a flame angle of $45^{\circ}$ with the vertical. The flame total duration application time is 20 s from the time at which the flame is first applied.
Some EPS-HBCD (with and without coatings) blocks were firstly tested in a standardized apparatus kindly made available by SaintGobain Placo (France) as seen in Fig. 1. Thereafter a lab-made simulated single flame source fire test was developed and used to evaluate the fire behavior of coated EPS (Fig. 2). It should be noted that our equipment has been manufactured in conformity with the standard apparatus after a comparative validation study. Indeed, this simulated lab-scale fire test was validated by measuring the fire rating of eight identical samples previously tested by the standardized fire test. All these samples presented identical Euroclass fire rating ( $\mathrm{F}$ or $\mathrm{E}$ ) with those tested with the standard apparatus on Saint-Gobain Placo site. Therefore in the next section, the results from simulated or standardized tests will not be separated.

\section{Result and discussion}

\subsection{Development of the coating suspension $C A M / P V O H$}

In this first part, the development of the coating based on $\mathrm{PVOH}$ filled with CAM boehmite is described. The CAM filler, the aqueous suspension and the solid film are characterized.

The CAM nanoparticle size was measured on SEM micrographs taken under magnification of 100,000× (Fig. 3). SEM images show

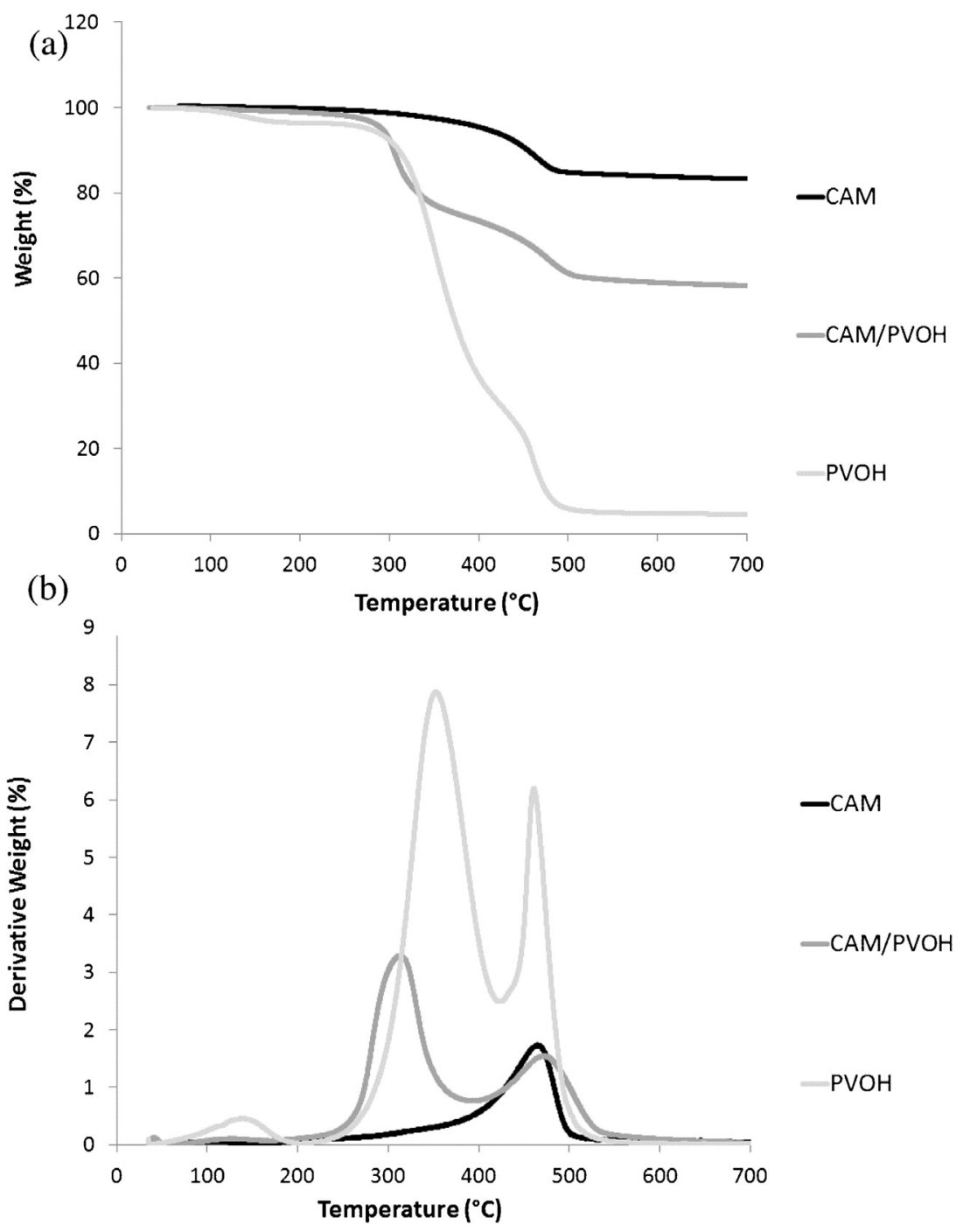

Fig. 7. Weight (a) and derivative weight (b) curves versus temperature under $\mathrm{N}_{2}$ at heating rate of $10^{\circ} \mathrm{C} / \mathrm{min}$ for $\mathrm{CAM}$ boehmite, $\mathrm{PVOH}$ and $\mathrm{CAM} / \mathrm{PVOH} 65 / 35$. 
the CAM aggregate size of around $68 \mathrm{~nm}$, and the presence of some independent and smaller particles $(21 \mathrm{~nm})$.

The filler size was also measured as the hydrodynamic diameter by Dynamic Light Scattering (DLS-Fig. 4). Based on this measurement $(103 \mathrm{~nm})$, it seems that CAM is quite well dispersed in water even without ultrasonic exposure. However, the ultrasonic bath mixing during $15 \mathrm{~min}$ decreases the hydrodynamic diameter of filler from $103 \mathrm{~nm}$ to $83 \mathrm{~nm}$. The difference in particles size between DLS and SEM is caused by particles interaction with water. This may indicate the strong dipole interactions between filler and water that lead to higher hydrodynamic diameter of fillers, and/or fillers agglomeration. Consequently, the particle size measured with DLS is larger than the size measured by SEM.

CAM incorporation to aqueous dispersion of PVOH increases the hydrodynamic diameter of particles (from 103 to $255 \mathrm{~nm}$ ) and the appearance of aggregates (around several microns) (Fig. 4). These aggregates are quite stable, because they persist even after ultrasonic bath mixing. Probably the small CAM particle size provides active surface area to interact with hydroxyl groups from $\mathrm{PVOH}$. Nevertheless, a small population of particles is still observed at ranges of $30 \mathrm{~nm}$ to $80 \mathrm{~nm}$.

Despite the formation of some aggregates, CAM is well dispersed in PVOH after drying, as proved by SEM pictures (Fig. 3). The fillers seem to be coated by polymer, and PVOH has also a role of binding agent for filler particles. Big aggregates are not observed, and the film surface looks very smooth. Such a good dispersion was already observed by Cai et al. [27] when they studied PVOH filled with pseudo-boehmite nanorods (up to $37.5 \mathrm{wt} \%$ ). The authors showed that these nanorods did not deteriorate the transparency of $\mathrm{PVOH}$ due to this outstanding nanoscale dispersion.

In dip coating method, the viscosity of coating suspension is one of the most important parameters. $\mathrm{pH}$ is an important parameter controlling the gelation of coating suspension. The synthesis medium of filler seems to influence their $\mathrm{pH}$. It has to be noted that CAM is synthesized by sol-gel method in acidic medium. As other sol-gel products, CAM filler is sensitive to the change of $\mathrm{pH}$. Aqueous dispersion of CAM and $\mathrm{PVOH}$ has low $\mathrm{pH}$ of 3.53 and 5.7 respectively. CAM incorporation into aqueous dispersion of $\mathrm{PVOH}$ results in $\mathrm{pH}$ blending of 4.3 .

The stability of coating suspension can be indicated by its zeta potential. The evolution of zeta potential by $\mathrm{pH}$ changes is presented in Fig. 5 for aqueous suspension of CAM (0.5 wt\%) and $\mathrm{CAM} / \mathrm{PVOH}(65 / 35,0.325 \mathrm{wt} \%$ of filler in suspension).

It can be seen that iso-electric point (IEP) occurs at $\mathrm{pH}$ of around 8.8 for CAM in water. Below and above this $\mathrm{pH}$ value, the CAM exhibits greater repulsive force between particles which indicates good particles dispersion in water. The iso-electric point occurs at $\mathrm{pH}$ around 6.8 for $\mathrm{CAM} / \mathrm{PVOH}$ aqueous suspension. Above this $\mathrm{pH}$, results show absence of repulsive forces which indicates that $\mathrm{CAM} / \mathrm{PVOH}$ is badly dispersed in basic $\mathrm{pH}$ where the suspension exhibits aggregates and clusters formation. Best-dispersed aqueous CAM/PVOH suspension was found for a $\mathrm{pH}$ of around 4.2 which corresponds to the initial $\mathrm{pH}$ value of the suspension.

The solid content of coating suspension determines its viscosity. The optimization of solid content was carried out using different concentrations of aqueous suspension of PVOH/CAM (35/65) (Fig. 6). It can be seen that viscosity increases moderately (from 0.09 to 2.2 Pa s) by increasing the total solid content from 14 to $21.5 \mathrm{wt} \%$ in water. Sharp increase in viscosity is observed above $22 \%$ of total solid content. So, an onset gelling point is established at $22 \mathrm{wt} \%$ of total solid content. This value is considered as the upper limit for solution viscosity that could be used for dip coating process. High PVOH/CAM 35/65 suspension viscosity is probably better to be used in comparison to low viscosity because it may result in a thicker coating film.
The thermal stability of filler and dried film containing CAM was characterized by thermogravimetric analysis under nitrogen at a heating rate of $10^{\circ} \mathrm{C} / \mathrm{min}$ from 50 to $900^{\circ} \mathrm{C}$. Fig. 7 shows the different degradation steps of filler, PVOH, and PVOH/CAM 35/65 film.

CAM filler presents one-step degradation related to the boehmite decomposition to form alumina particles. CAM filler displays weight loss around $16 \mathrm{wt} \%$ at $600^{\circ} \mathrm{C}$, and the degradation starts before $300^{\circ} \mathrm{C}$. Strong degradation was observed from $360^{\circ} \mathrm{C}$ to $520^{\circ} \mathrm{C}$ (peak at $470^{\circ} \mathrm{C}$ ), showing the conversion of boehmite into alumina.

Under anaerobic pyrolysis, poly(vinyl alcohol) (PVOH) is degraded under three steps as described in Scheme 1.

According to Alkan and Benlikava [31], the first degradation step of PVOH between 50 and $180^{\circ} \mathrm{C}$ is related to the loss of moisture and/or evaporation of the trapped water. The second step from $250^{\circ} \mathrm{C}$ to $400^{\circ} \mathrm{C}$ is caused by elimination of water and residual acetate groups from partially hydrolyzed $\mathrm{PVOH}$. The further degradation step at higher temperatures $\left(400-550^{\circ} \mathrm{C}\right)$ is attributed to the degradation of polyene residues to yield carbon and hydrocarbons. So, this latter step is the key of charring in PVOH degradation. The final residue obtained from degradation of $\mathrm{PVOH}$ investigated by TGA is $4.8 \mathrm{wt} \%$.

The dried coating film containing CAM filler presents identical degradation modes with a three-step degradation. A small degradation peak barely visible observed at lower temperature (between $50^{\circ} \mathrm{C}$ and $150^{\circ} \mathrm{C}$ ) may be attributed to the release of physisorbed water. The second step between $250^{\circ} \mathrm{C}$ and $390^{\circ} \mathrm{C}$ corresponds to polymer degradation, and the last step with a peak at $475^{\circ} \mathrm{C}$ is due to both filler decomposition and polymer degradation.

$\mathrm{CAM} / \mathrm{PVOH}$ curve does not correspond to a simple rule of mixtures calculated from CAM and PVOH curves. The main degradation step corresponding to $\mathrm{PVOH}$ degradation is shifted to lower temperature. Peak of mass loss rate is found at $315^{\circ} \mathrm{C}$ for CAM/PVOH versus $360^{\circ} \mathrm{C}$ for $\mathrm{PVOH}$. The last step corresponding to $\mathrm{PVOH}$ and filler degradations appears to be spread. The peak is lower than the corresponding peaks of PVOH and CAM degradation, it is shifted and ends also at slightly higher temperature (approximately $+10^{\circ} \mathrm{C}$ ).

Incorporation of CAM into $\mathrm{PVOH}$ resulted in higher final residue than expected (58\% instead of 55\%). The expected residue is obtained according to a linear rule of mixtures. Based on this calculation, the char from polymer in the dried film should be $1.7 \%$ (from $35 \mathrm{wt} \%$ of initial PVOH composition in the dried film). In the presence of boehmite, the char from polymer after pyrolysis is much higher: $4.5 \%$. It means that the incorporation of CAM boehmite promotes the charring of $\mathrm{PVOH}$.

All these changes evidence that CAM boehmites are not inert fillers in $\mathrm{PVOH}$. These fillers promote the degradation of $\mathrm{PVOH}$ at lower temperature but slightly improve the char content and its thermal stability. These results are in good agreement with those found by Cai et al. [27]. These authors noted that pseudo-boehmite rods induce an earlier decomposition of $\mathrm{PVOH}$ but enhance char content.

\subsection{Coating deposition on EPS foams}

The amount of deposited coating suspension during dip coating must also be optimized in order to obtain the best flame retardant coating. The quantity of solid uptake, called coating level, is calculated by weighing the sample before and after coating as presented in Eq. (1) below:

$$
\text { Coating level }(w t \%)=\frac{\text { Weight of coated EPS }=\text { Weight of EPS before coating }(\mathrm{g})}{\text { Weight of EPS before coating }(\mathrm{g})}
$$

$\times 100$ 


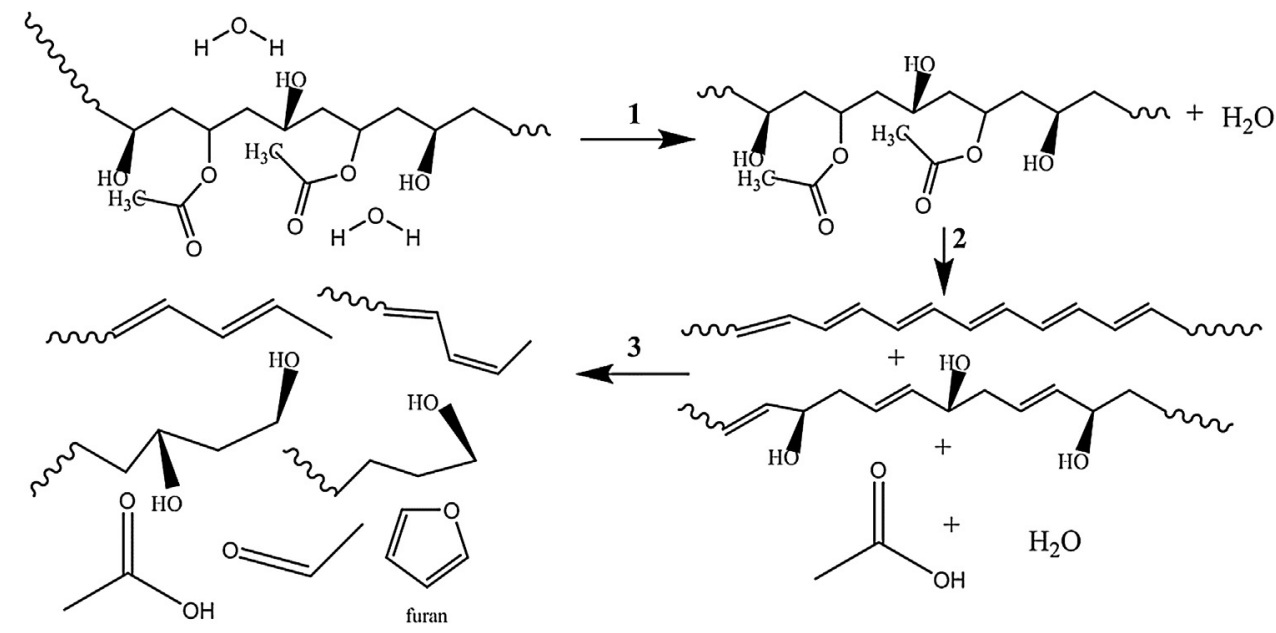

Scheme 1. Pyrolytic degradation steps of poly(vinyl alcohol) (PVOH) [31].

This value influences the flame retardancy, and also should be considered for cost evaluation in industrial application. Some parameters controlling this value were investigated: coating number (i.e. number of dips), coating suspension, viscosity, drying method, microstructure of EPS matrix, and the duration of coating impregnation time. The influence of these parameters on coating level and thickness is discussed in this section.

\subsubsection{Viscosity of coating suspension}

The influence of viscosity was investigated on EPS-HBCD blocks using suspensions with low (0.7 Pas, solid CAM + PVOH content 16 wt\%) and high (2.2 Pa s, solid content $21 \mathrm{wt} \%$ ) viscosities and the coating was applied using static dip coating process. The influence of viscosity and dips number (1,2 and 4 dips) on surface coating formation, coating thickness and coating level was evaluated using SEM and by samples weighing before and after coating application.

Coating level increases with the dips number and does not reach a plateau value even after 4 dips. For the same number of dips, the coating level is higher in the case of high viscosity suspension (Fig. 8). The difference in coating level when using suspensions of low or high viscosity increases with the dips number: $135 \mathrm{wt} \%$ versus $55 \mathrm{wt} \%$ after four dips.

The average thickness of the coating also increases with dips number for high and low viscosity suspension (Fig. 9). The more viscous suspension allows reaching higher coating thickness. Maximum coating thickness of around $25 \mu \mathrm{m}$ could be achieved by performing four dips with suspension of low viscosity, but a thickness higher than $100 \mu \mathrm{m}$ could be reached with suspension of high viscosity.

In addition, the more viscous suspension allows obtaining a smoother surface (Fig. 10). However, it seems that one dip is not enough to make a smooth surface without holes whatever the suspension concentration used. At least two dips are required to obtain a homogeneous surface texture.

Considering these results, the more viscous suspension (2.2 Pa.s) was chosen to be used for EPS coating treatment in the following.

\subsubsection{Drying method}

As observed previously in Fig. 9, the coating thickness is not homogeneous for EPS-HBCD coated with the more viscous suspension. The coating thickness is much higher on EPS lower side due to gravity. Mechanical rotary drying method was then used to improve the homogeneity of coating layer. Figs. 11 and 12 compare the coating level and the coating thickness on upper and lower sides for static and rotary drying (Fig. S2 in supporting information shows the location of EPS block during drying). Rotary drying allows a very homogeneous coating (no difference in coating thickness on lower and upper side) even if the coating level is significantly lower. Rotary drying allows monitoring the film thickness (homogeneous coating) over the whole surface of EPS blocks.

The surface film formed by mechanical rotary is also aesthetically smoother and without holes, as seen in SEM micrographs of one dip coating using static or rotary drying (Fig. 13).

\subsubsection{Impregnation time}

Impregnation time was also studied as an influent parameter (Fig. 11). It allows monitoring the coating penetration, the surface smoothness, and the coating thickness. A longer impregnation time slightly increases the average thickness of coating layer from $17 \mu \mathrm{m}$ to $36 \mu \mathrm{m}$, but a remarkable increase on coating level is observed from $34 \%$ to $170 \%$ and the deposit is very homogeneous (when using the more viscous suspension and rotary drying). So, a higher coating level does not result only in a thicker coating but also in the amount of suspension which penetrates into the material. Longer impregnation time allows more coating suspension to penetrate through the voids between the EPS beads (Fig. 14). The white marks in the SEM image are related to the boehmite particles. The SEM images in the core of coated EPS foam shows poorer penetration when impregnation time is only $5 \mathrm{~min}$. On the contrary, after an impregnation time of $18 \mathrm{~h}$, more coating suspension penetrated in the core of EPS-HBCD plates. It must be noted that it was not possible to assess quantitatively the fraction of coating penetrating into the material (and the fraction of coating remaining at the surface).

The penetration of coating suspension was monitored by SEM observations on a $60 \mathrm{~mm}$ EPS-HBCD thickness block after $18 \mathrm{~h}$ of impregnation time. It seems from Fig. 15 that coating suspension penetrated into the whole core of EPS-HBCD block by covering the surface beads. This observation confirms the higher mass uptake previously observed. It is important to note that pores inside each EPS bead are not accessible by the coating suspension.

Finally it is also noteworthy that surface coating is more homogeneous for one dip coating with a long impregnation time of $18 \mathrm{~h}$ on lower and upper sides in comparison to a short impregnation time of 5 min as shown in Fig. 16.

\subsubsection{Microstructure and density of EPS}

The coating suspension is not only deposited at the foam surface but can also penetrate into the core. The penetration depends on the foam microstructure. Therefore it is important to compare the easiness of the suspension to penetrate into the two foams stud- 


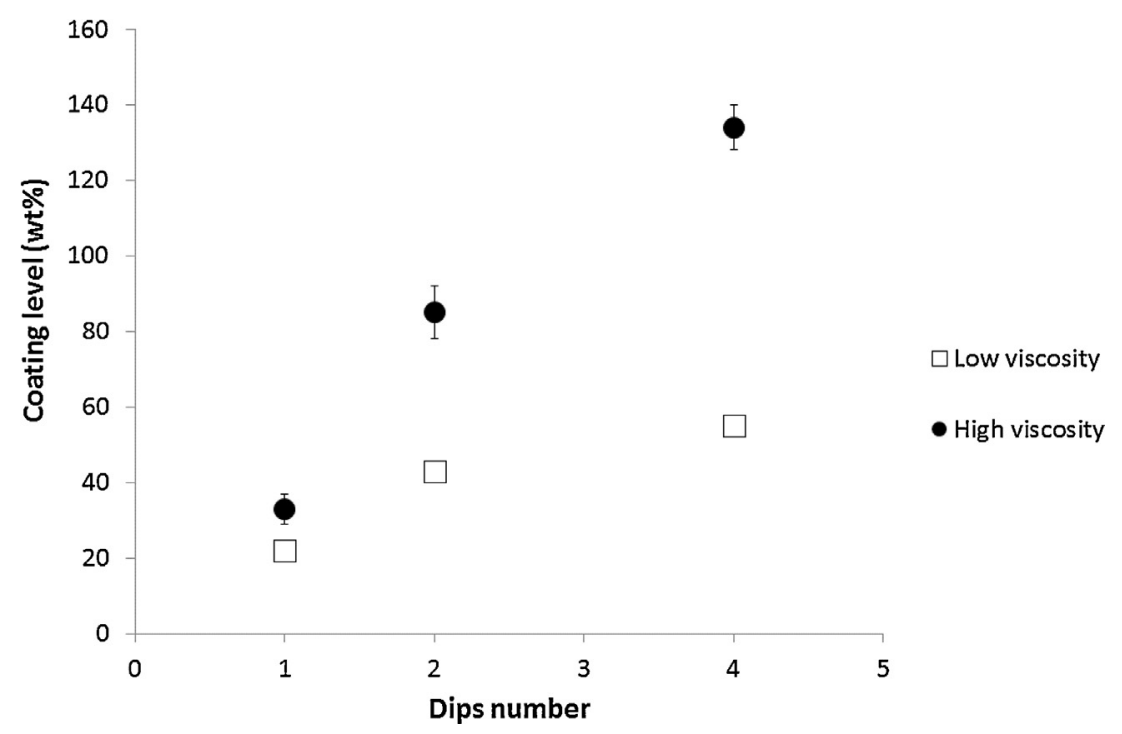

Fig. 8. Coating level versus dips number for EPS-HBCD coated with suspensions of low or high viscosity.

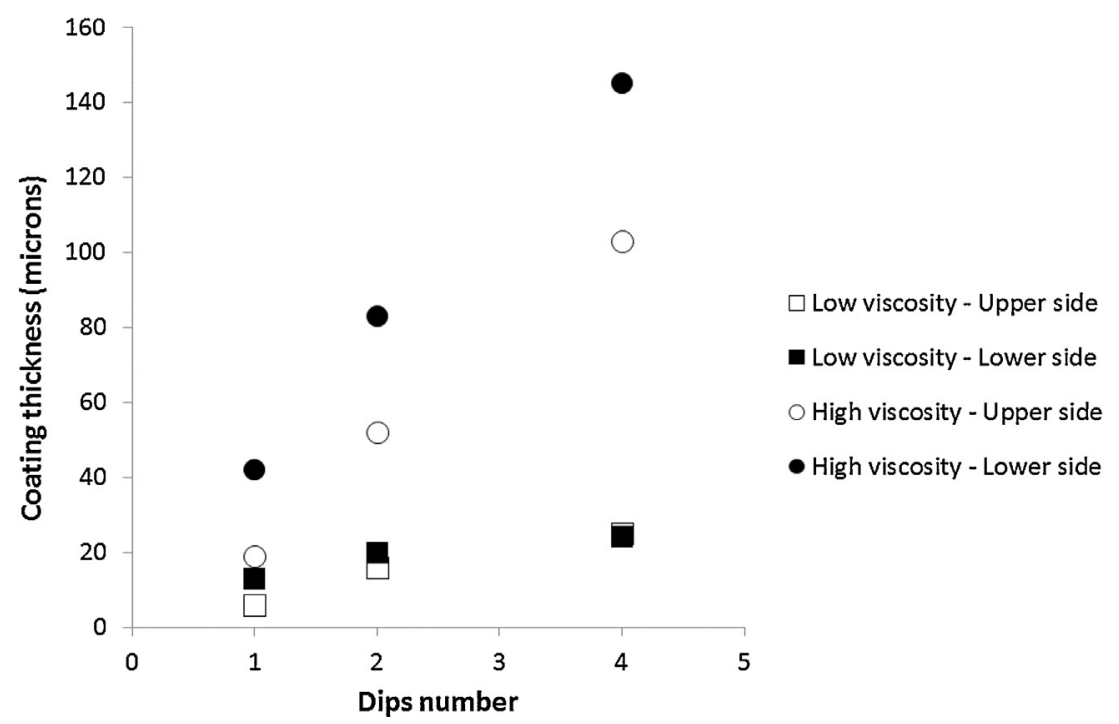

Fig. 9. Coating thickness versus dips number for EPS-HBCD coated with suspensions of low or high viscosity.

ied in this work: "low" density EPS without HBCD $\left(14 \mathrm{~kg} / \mathrm{m}^{3}\right)$ and "high" density EPS with $\operatorname{HBCD}\left(16 \mathrm{~kg} / \mathrm{m}^{3}\right)$. Higher density EPS foam has fewer voids among the interstices of EPS beads (Fig. 17). This microstructure parameter plays an important role in coating penetration. A better penetration of PVOH/CAM suspension to the core of lower density EPS foam is observed for a 4 dips coating using short time ( 5 min of impregnation for each dip). At the same dips number, the lower density EPS also presents higher solid uptake compared to higher density EPS ( 140 wt\% vs 90 wt\%). For longer impregnation time ( $18 \mathrm{~h}$ ) coating suspension has more time to penetrate through EPS beads interstices and no difference was found between both EPS foams (Fig. 17). Thus, taking into account the relative error, similar solid uptake for 1 coating with longer impregnation time is observed for EPS with and without HBCD ( 130-160 wt\%).

In order to assess the effect of microstructure on suspension penetration, the inner density was measured on the coated foams. Fig. 18 shows the density of all the foams tested according to the fire test NF EN ISO 11925-2 after removing the external surface of the coating using a sharp thin blade.
It is obvious that the suspension in high density EPS (EPS-HBCD) mainly accumulates on surface as confirmed by the low variation of inner density observed when applying 1,2 and 4- dips with a short impregnation time. Density remains almost constant despite a significant coating level. On the contrary, in EPS without HBCD (i.e. low density EPS), an increase of inner density is observed when increasing coating level. In that case, the bigger pores allow higher suspension penetration leading to higher inner density. Results also confirm once again that coating suspension penetration in EPS with or without HBCD (small or bigger pores) is similar for long impregnation time. The EPS block inner density is almost the same whatever the microstructure of the foam.

Impregnation time and EPS microstructure play a major role in promoting coating suspension penetration into the core of specimens. Higher impregnation time in presence of smaller pores or lower impregnation time in presence of bigger pores may allow reaching the same coating penetration level. 


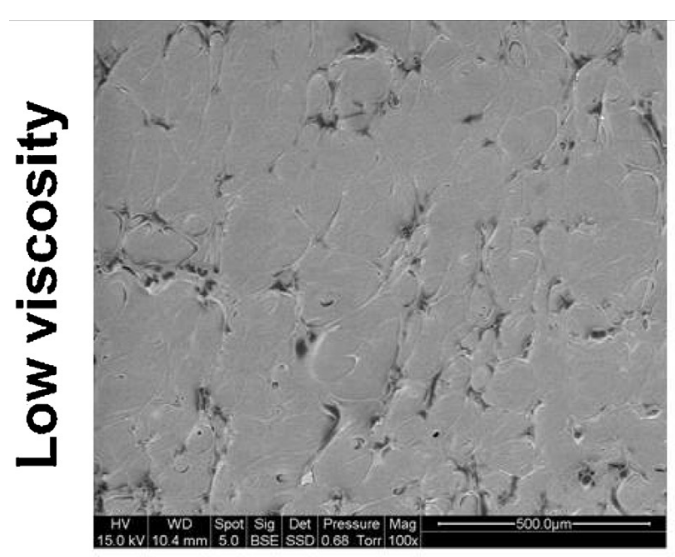

a

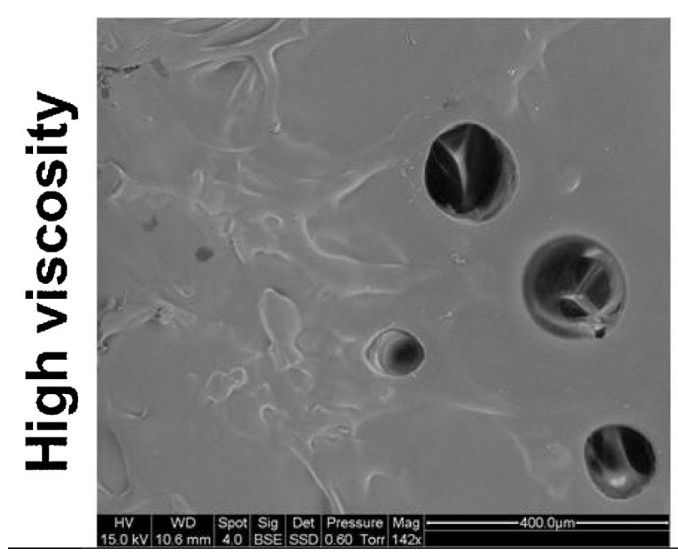

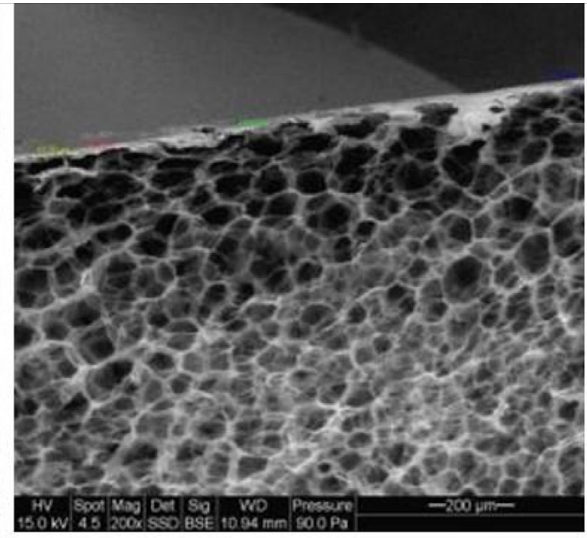

b

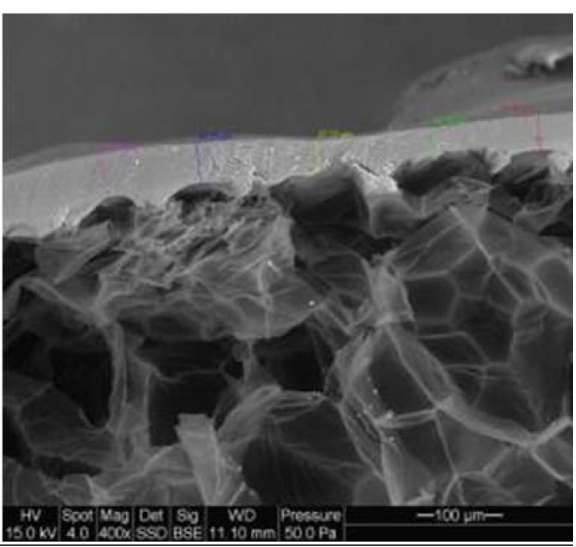

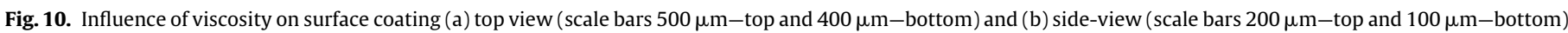
(one dip).

\subsection{NF EN ISO 11925-2 fire test on the coated EPS blocks}

The fire test NF EN ISO 11925-2 was carried out on various EPS and EPS-HBCD blocks with and without coatings. All results are detailed in Table 1 and plotted in Fig. 19.

Non coated EPS with HBCD is "E" Euroclass fire rated; it shrinks away from the heat source when exposed to flame (Fig. 20); no paper filter ignition and very low flame propagation are observed accompanied with immediate flame extinction.

EPS-HBCD blocks coated using one, two and four dips in the lower viscosity $\mathrm{PVOH} / \mathrm{CAM}$ suspension are Euroclass fire rating downgraded. These samples are "F" rated because the flame tip reaches $150 \mathrm{~mm}$ above the application point during the test. Note that using the low viscosity suspension the maximum coating

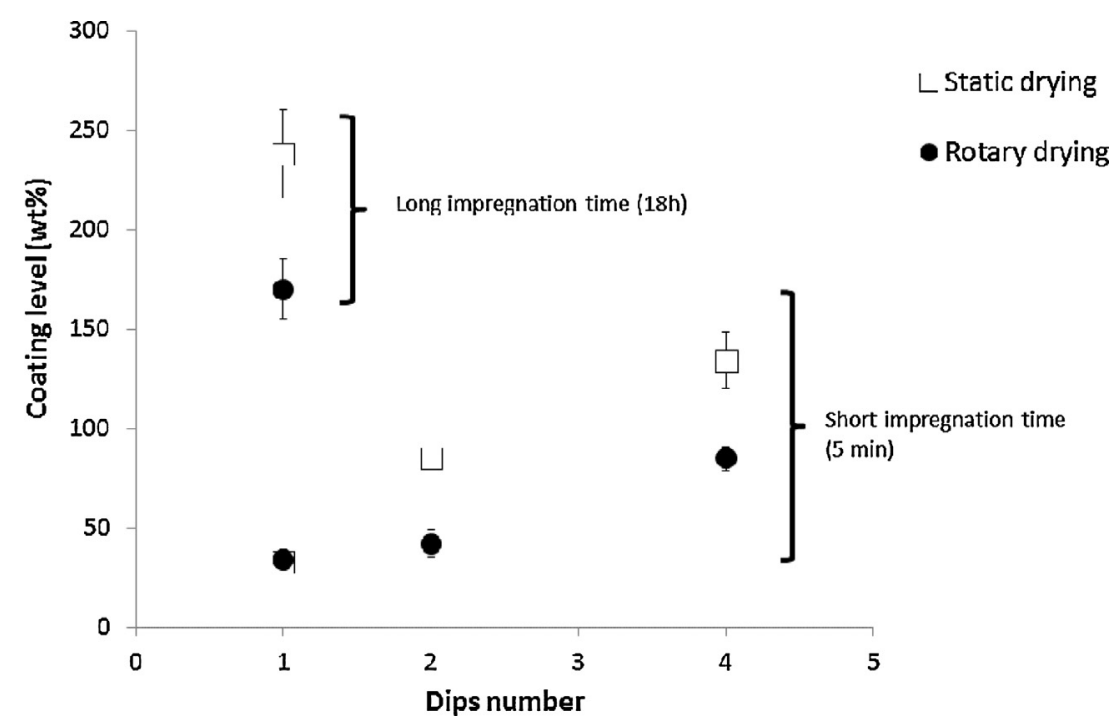

Fig. 11. Coating level versus dips number for EPS-HBCD coated with suspension of high viscosity and dried using static or rotary drying. 


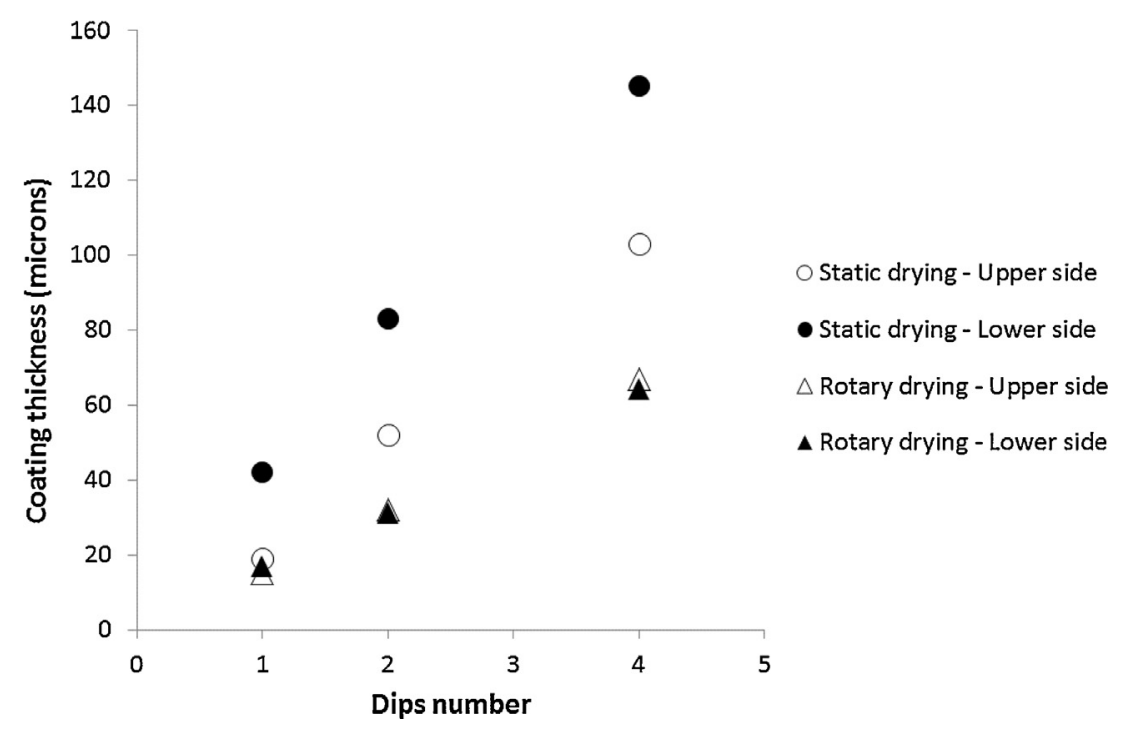

Fig. 12. Coating thickness versus dips number for EPS-HBCD coated with suspension of high viscosity and dried using static or rotary drying.

a. Static drying
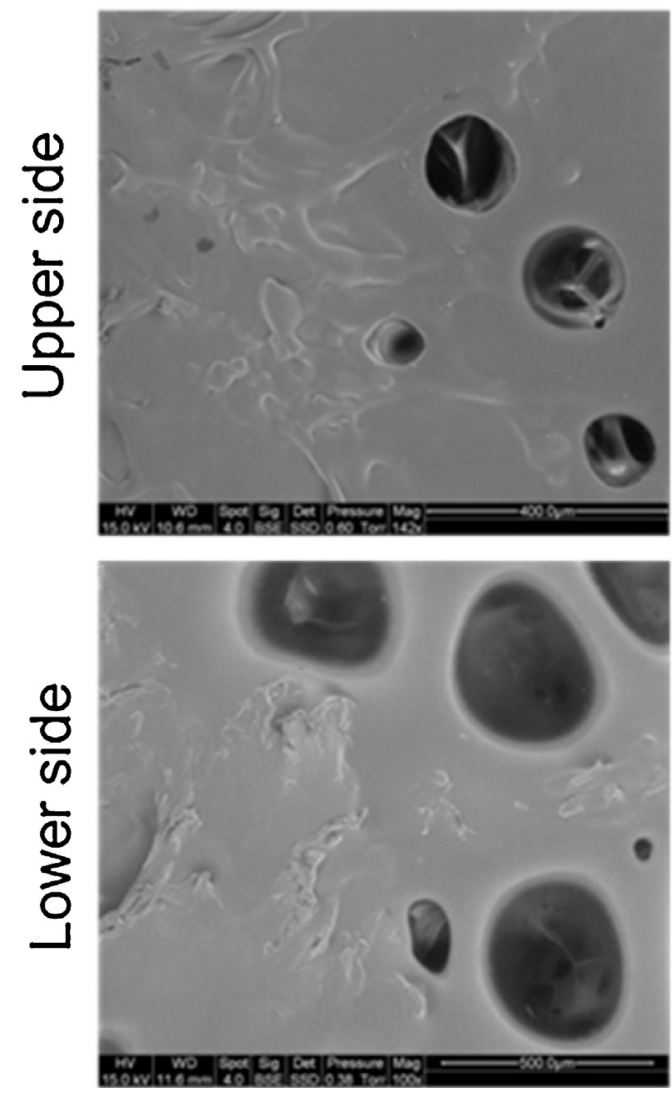

b. Rotary drying
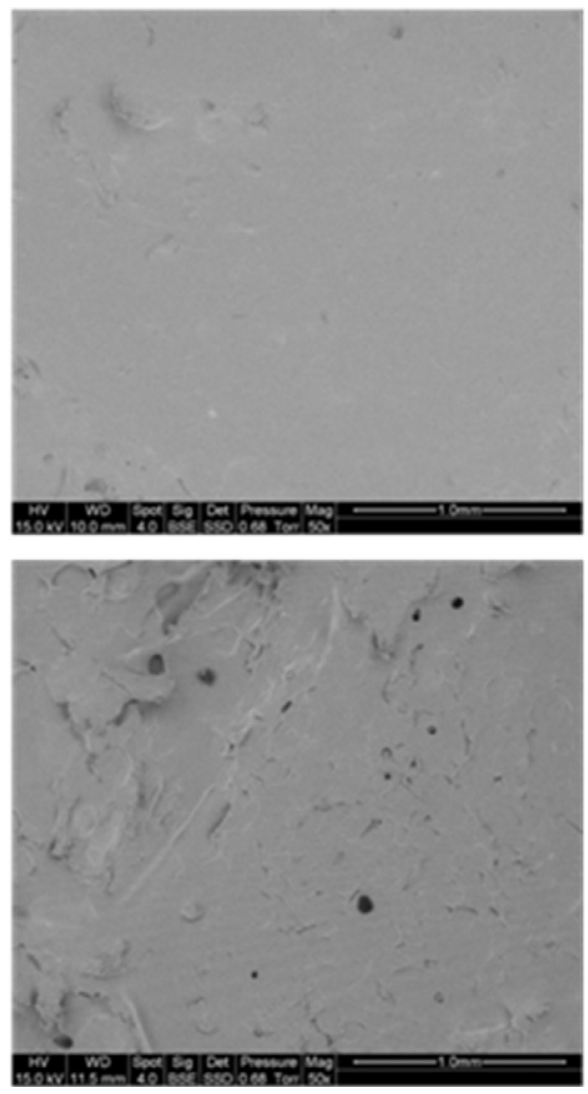

Fig. 13. Influence of drying method on coating surface texture (scale bars: $400 \mu \mathrm{m}-$ top and left, $500 \mu \mathrm{m}-$ bottom and left, $1 \mathrm{~mm}-$ right).

thickness reaches about $24 \mu \mathrm{m}$ and the coating level reaches only $55 \mathrm{wt} \%$.

Different results on Euroclass fire rating were observed during fire tests on EPS-HBCD plates coated with high viscosity PVOH/CAM suspension. One dip (1-C) coating with average thickness of $17 \mu \mathrm{m}$ and coating level of $34 \mathrm{wt} \%$ failed the fire test (class F). Applying two (2-C, coating average thickness $31 \mu \mathrm{m}$, coating level $42 \mathrm{wt} \%$ ) hardly passed the fire test. The flame tip reaches $150 \mathrm{~mm}$ for 2 of 7 samples and for the 5 other samples the flame reached limit values of about $100-130 \mathrm{~mm}$. On the other side, EPS-HBCD plates coated using four dips (4-C) or one dip with long impregnation time (1-C-16 h) resulted in better Euroclass fire rating (E). Applying four dips with average thickness of $63 \mu \mathrm{m}$ and coating level of $85 \mathrm{wt} \%$ inhibits flame propagation. Same results were observed for EPS-HBCD samples after one dip with long impregnation time exhibiting lower average thickness $(39 \mu \mathrm{m})$ but higher coating level 

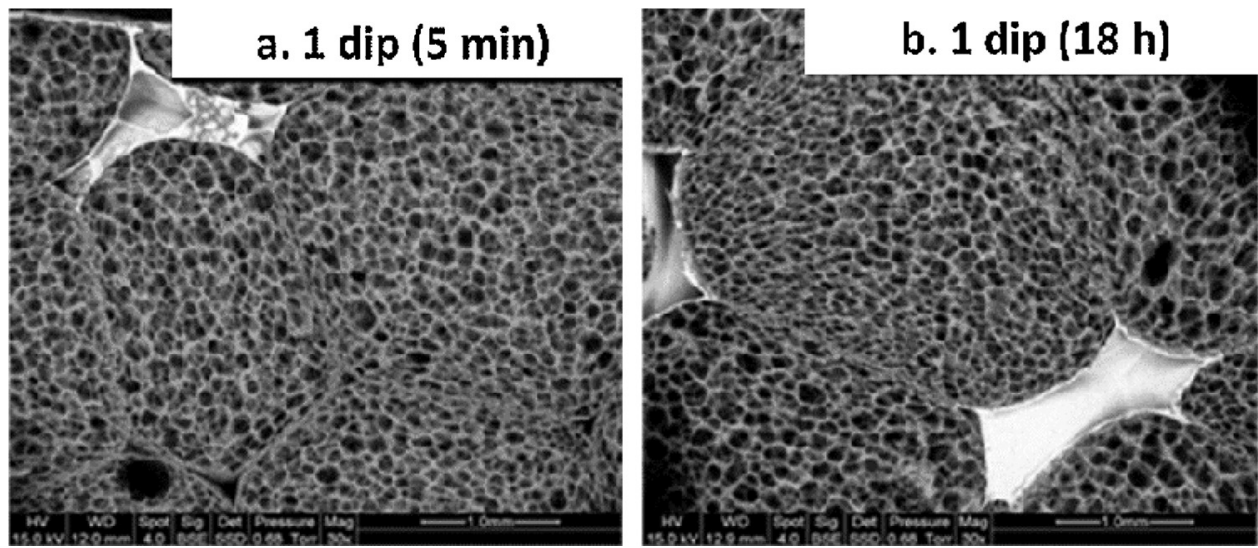

Fig. 14. Influence of the impregnation time on suspension penetration into the core of EPS-HBCD (scale bars $1 \mathrm{~mm}$ ).

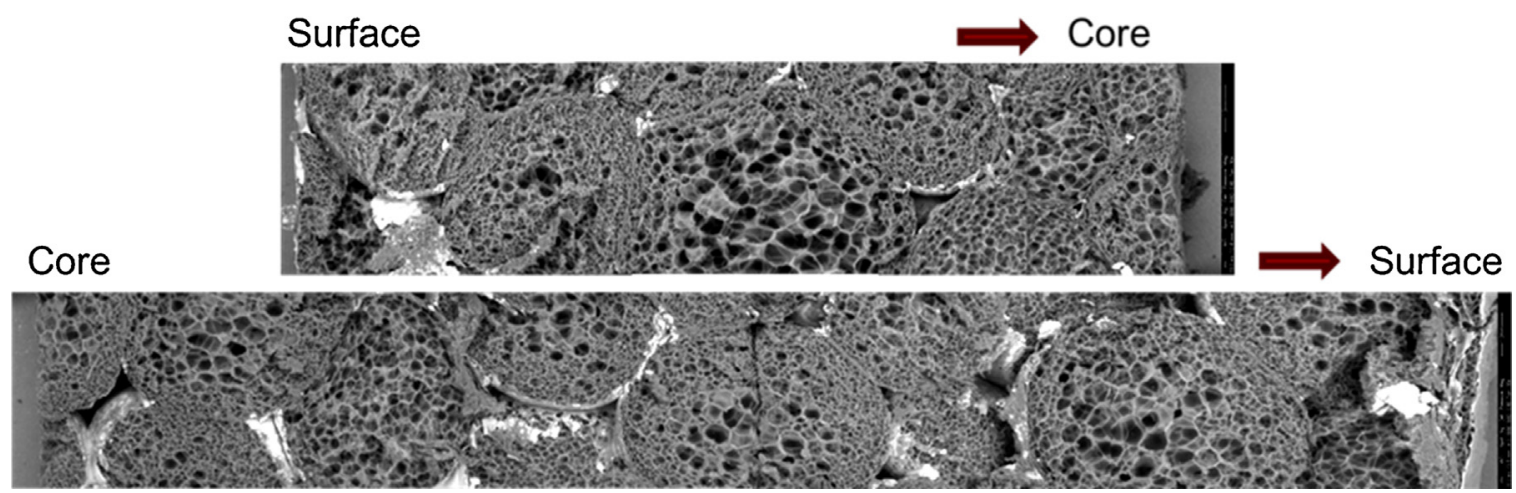

Fig. 15. The CAM/PVOH penetration into the core of EPS without $\mathrm{HBCD}$ for one dip during $18 \mathrm{~h}$.
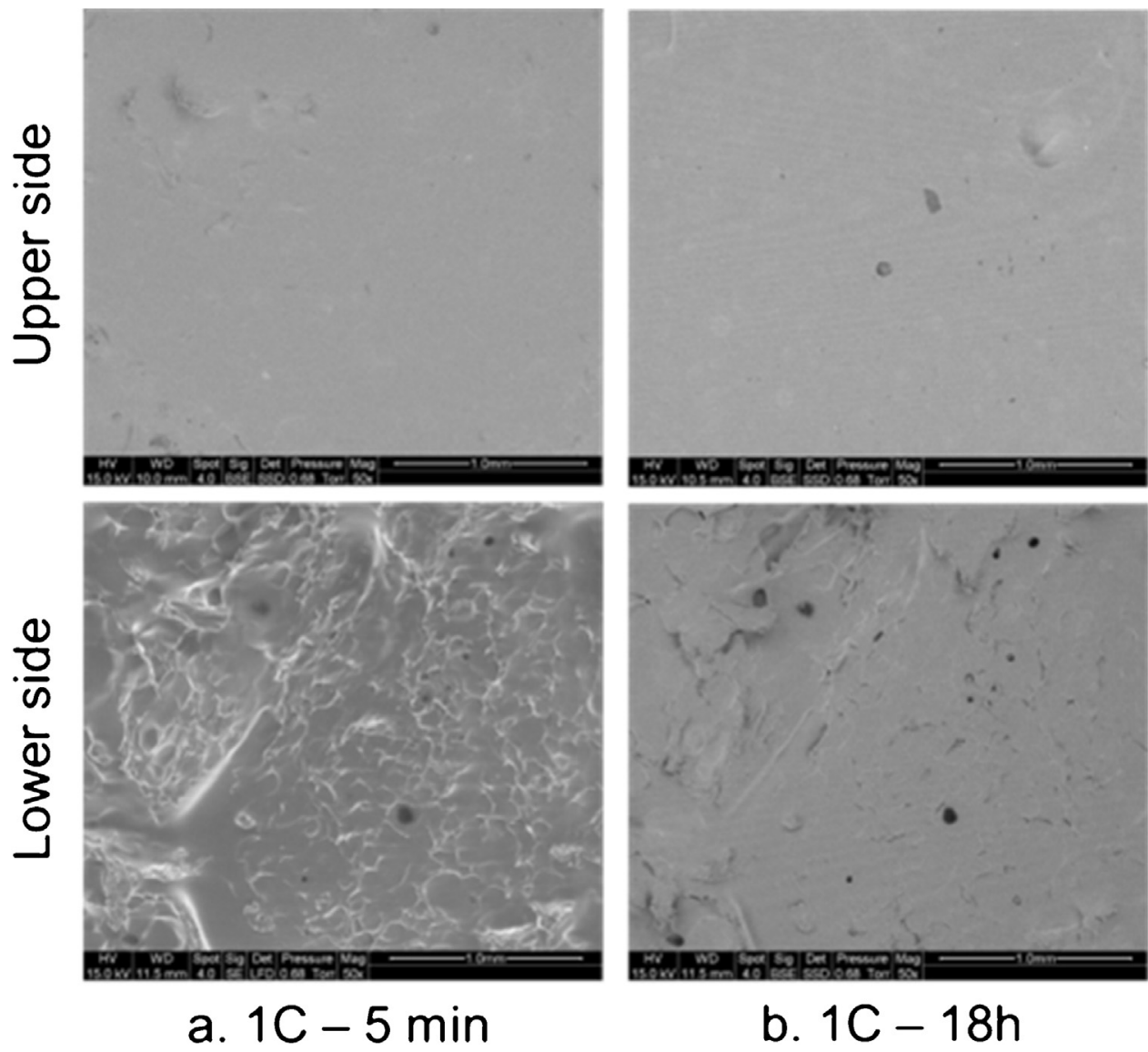

b. $1 \mathrm{C}-18 \mathrm{~h}$

Fig. 16. Influence of impregnation time using rotary drying on the coating surface texture of 1 dip coating EPS-HBCD (scale bars $1 \mathrm{~mm}$ ). 

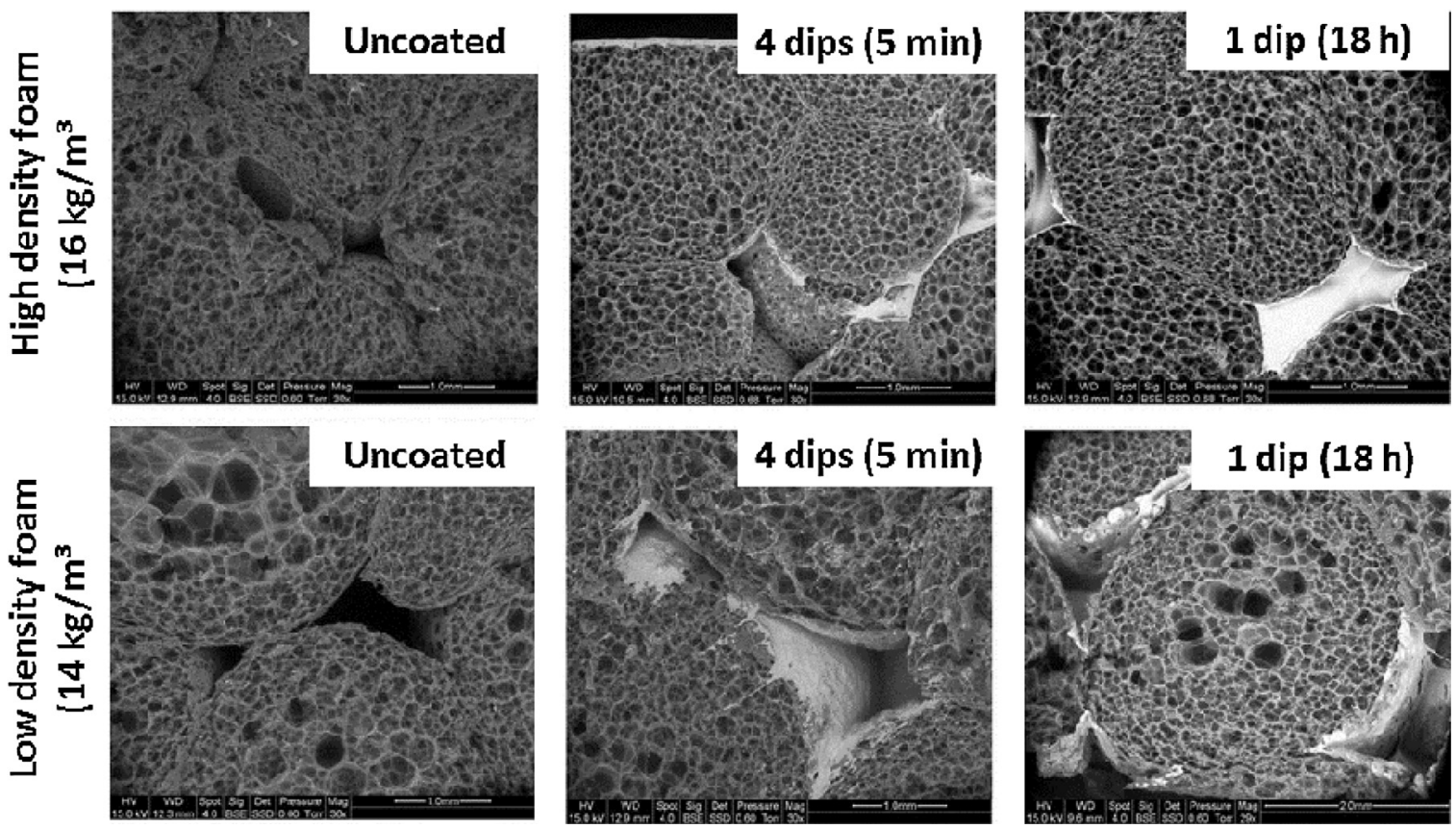

Fig. 17. The different microstructures of EPS foams before and after coating and the CAM/PVOH penetration into the core of high density (EPS with HBCD) and low density EPS foam (EPS without HBCD) (scale bars $1 \mathrm{~mm}$ except $2 \mathrm{~mm}$ at right and bottom).

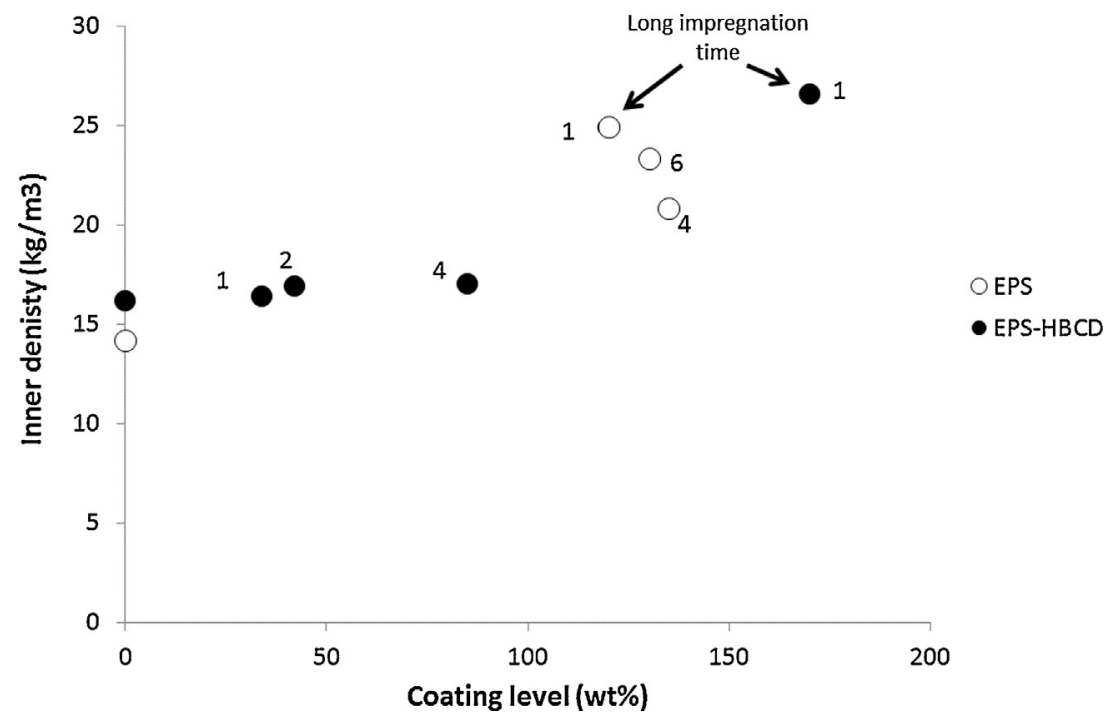

Fig. 18. The density evolution versus the coating level for various coated EPS foams (labels correspond to the dips number).

(170 wt\%). Better fire behavior was observed according to the lowest distance (Fs) covered by the flame $(50-80 \mathrm{~mm})$. Note that an appropriate coating level allows maintaining E rating while completely changing the mode-of-action of the flame retardant system. HBCD acts as flame inhibitor while the coating developed in this study promotes barrier effect thanks to a layer consisting in mineral particles and char. When coating level is not high enough, downgrading is observed, probably because coated EPS-HBCD does not shrink away from the flame (contrarily to EPS-HBCD). Cai et al. have already noted that $\mathrm{PVOH}$ does not shrink during burning when filled by pseudo-boehmite rods probably because alumina from pseudo-boehmite nanoparticles acts as a skeleton of the char [27].

Non-coated EPS without HBCD, once exposed to flame, shrinks away from heat while instantly ignites and promotes highly flame propagation. EPS had "F" Euroclass fire rating because it burns immediately; flame propagation is never stopped and produces burning drops which caused paper filter ignition.

Previous fire test on EPS-HBCD showed that coating level must be higher than $85 \mathrm{wt} \%$ to obtain E Euroclass fire rating. Therefore, the EPS samples without HBCD were protected with four or six dips with short impregnation time ( $5 \mathrm{~min}$ ) or one dip with long impregnation time $(18 \mathrm{~h})$. Coating level was higher than $120 \mathrm{wt} \%$ for these three samples.

Such coated EPS exhibit better flame retardancy and their Euroclass fire ratings upgrade from " $F$ " to " $E$ ". The flame tip never reaches $150 \mathrm{~mm}$ above the application point during the test and no burning drop is observed. All these coated EPS show self-extinguishing after $10-15 \mathrm{~s}$ of flame exposure.

Dip coating allows monitoring coating level and coating thickness. Generally high coating level is associated to high coating thickness. To assess the respective influence of both parameters on 
Table 1

NF EN ISO 11925-2 fire test results.

\begin{tabular}{|c|c|c|c|c|c|c|c|c|}
\hline Sample & $\begin{array}{l}\text { Suspension } \\
\text { viscosity }\end{array}$ & $\begin{array}{c}\text { Dips } \\
\text { number }\end{array}$ & $\begin{array}{c}\text { Impregnation } \\
\text { time }\end{array}$ & $\begin{array}{l}\text { Coating } \\
\text { thickness } \\
\text { (microns) }\end{array}$ & $\begin{array}{c}\text { Coating } \\
\text { level } \\
(w t \%)\end{array}$ & Rating & $\begin{array}{c}\text { Fs } \\
(\mathrm{mm})\end{array}$ & $\begin{array}{l}\mathbf{T}_{\text {self }} \\
\text { (s) }\end{array}$ \\
\hline EPS-HBCD & & & & 0 & 0 & $\mathrm{E}$ & 16 & 1 \\
\hline EPS-HBCD & High & 1 & Short & 17 & 34 & $\mathrm{~F}$ & 136 & 7 \\
\hline EPS-HBCD & High & 2 & Short & 31 & 42 & $\mathrm{~F}$ & 131 & 8 \\
\hline EPS-HBCD & High & 4 & Short & 63 & 85 & $\mathrm{E}$ & 87 & 10 \\
\hline EPS-HBCD & High & 6 & Long & 39 & 170 & $\mathrm{E}$ & 64 & 9 \\
\hline EPS-HBCD & Low & 1 & Short & 13 & 21 & $\mathrm{~F}$ & $>150$ & 1 \\
\hline EPS-HBCD & Low & 2 & Short & 20 & 43 & $\mathrm{~F}$ & $>150$ & 10 \\
\hline EPS-HBCD & Low & 4 & Short & 24 & 55 & $\mathrm{~F}$ & $>150$ & 6 \\
\hline EPS & High & 0 & & 0 & 0 & $\mathrm{~F}$ & $>150$ & 1 \\
\hline EPS & High & 4 & Short & 54 & 141 & $\mathrm{E}$ & 54 & 13 \\
\hline EPS & High & 6 & Short & 73 & 141 & $\mathrm{E}$ & 90 & 15 \\
\hline EPS & High & 1 & Long & 42 & 129 & $\mathrm{E}$ & 81 & 12 \\
\hline $\begin{array}{c}\text { EPS after surface } \\
\text { removal }\end{array}$ & High & 4 & Short & 0 & 141 & $\mathrm{E}$ & 85 & 18 \\
\hline $\begin{array}{c}\text { EPS after surface } \\
\text { removal }\end{array}$ & High & 6 & Short & 0 & 141 & $\mathrm{E}$ & 94 & 17 \\
\hline $\begin{array}{c}\text { EPS after surface } \\
\text { removal }\end{array}$ & High & 1 & Long & 0 & 129 & $\mathrm{E}$ & 104 & 17 \\
\hline
\end{tabular}

coating efficiency, the fire test was also carried out after removing the surface layer on the lower side of coated EPS (without HBCD). Therefore, the coating thickness becomes null. The surface removal still results in E Euroclass fire rating (Table 1 and Fig. 19). The flame propagation does not reach $150 \mathrm{~mm}$, no flaming drop is observed and all specimens show self-extinguishing after flame removal. Nevertheless, flame spread and self-extinguishing time slightly increase. The sample residue after removal of its surface layer still shows charring on the uncoated side (Fig. 20), due to the coating penetration into the voids between EPS beads as seen in Fig. 15. This result leads us to conclude that the coating penetration is the most important parameter to achieve "E" fire rating.

This result is of particular interest. Indeed, EPS blocks are often cut off just before installation. In such a case, flame retardancy would be lost if the coating was present only at the surface.

It is noteworthy that EPS-HBCD coated with four dips in highly viscous suspension is also $\mathrm{E}$ rated despite the non-penetration of coating into the foam core. Then, in some cases, a thick coating only at the foam surface can be also efficient enough.

\section{Conclusions}

A protective coating on EPS foam was developed using aqueous dispersion of boehmite in poly(vinyl alcohol) (PVOH). From a certain coating level, the EPS without $\mathrm{HBCD}$ coated with $\mathrm{CAM} / \mathrm{PVOH}$ suspension allows obtaining E Euroclass fire rating instead of $\mathrm{F}$ in standardized fire test NF EN ISO 11925-2.

The use of aqueous suspension of boehmite in poly(vinyl alcohol) with a dry composition of $65 / 35 \mathrm{wt} \%$ shows a very good potential to replace HBCD as flame retardant in EPS foam. Thanks to the porous structure of EPS foam, a significant absorption of CAM/PVOH into the interstices of EPS is allowed. EPS blocks microstructure had great influence on coating suspension penetration in the core of specimens for short time treatment. Coating

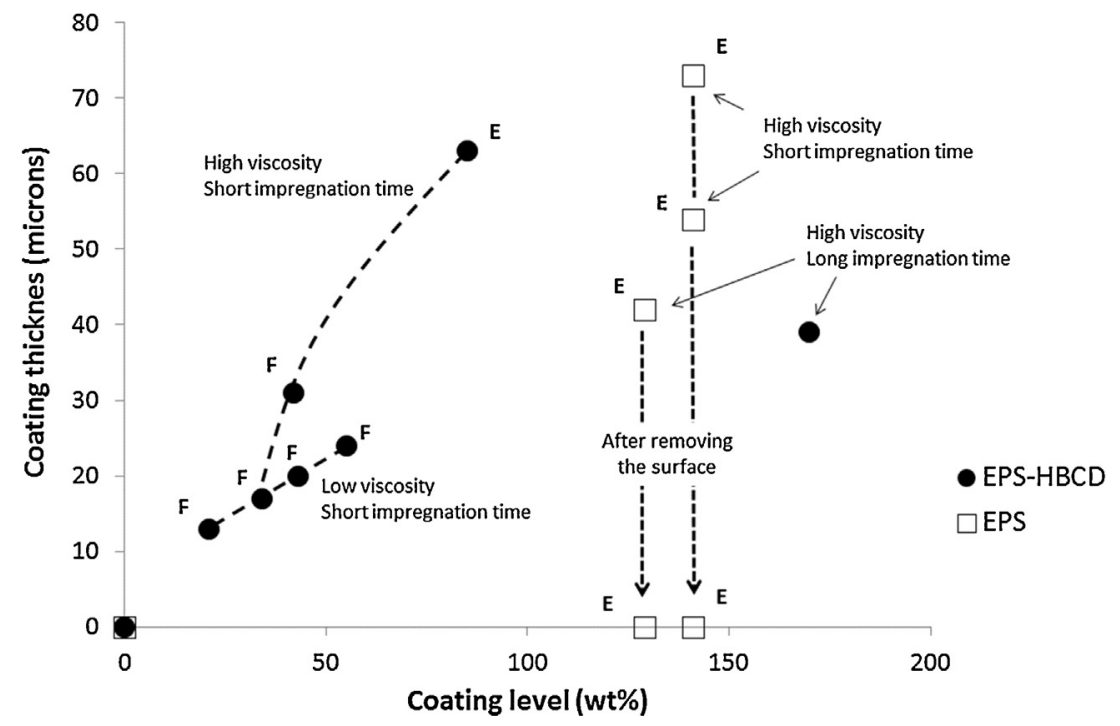

Fig. 19. The influence of coating level \& coating thickness on the Euroclass fire rating (Non-coated EPS and EPS-HBCD are respectively F and E rated). 


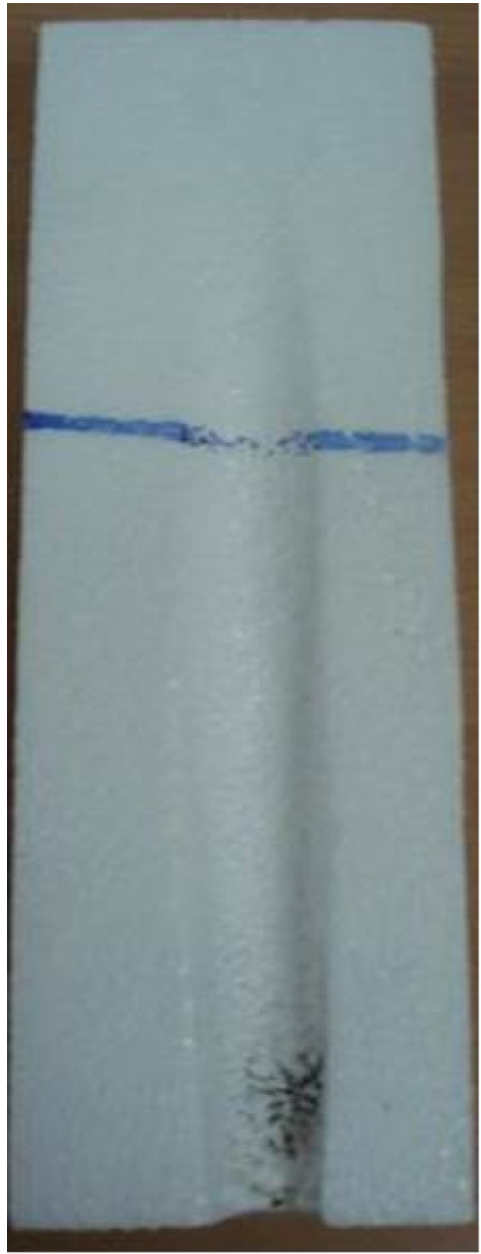

(a)

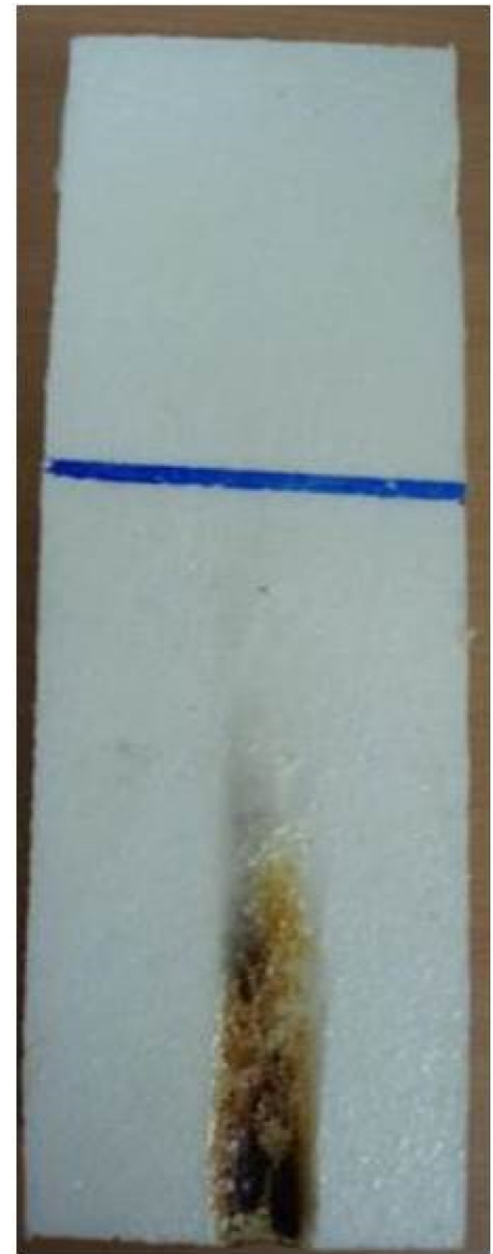

(b)

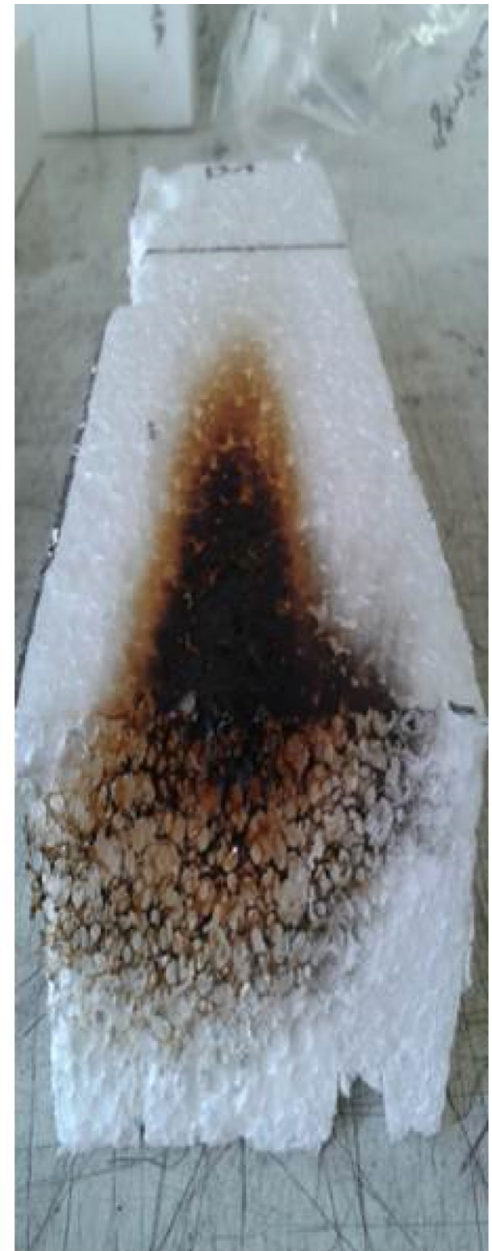

(c)

Fig. 20. Residue of non-coated EPS-HBCD (a), EPS without HBCD coated with CAM/PVOH 65/35 (b) and after the removal of its surface layer on the lower side (c).

penetration through the interstices promotes better beads coverage leading to better flame retardancy.

During burning, the coating protects not only the surface of EPS foam, but also the individual EPS spheres. After removing the coated surface, the E rating can be maintained evidencing that the flame retardancy depends mainly on the coating level penetrating into the foam core.

The flame retardancy mode-of-action of EPS by boehmite/PVOH coating is attributed to the barrier effect allowed by filler and $\mathrm{PVOH}$ charring promoted by the boehmite while HBCD usually acts as flame inhibitor. The coating based on boehmite modifies the EPS behavior in presence of the flame: EPS does not shrink anymore. The release of water by boehmite to dilute fuels may also be an additional mode-of-action. At low coating level, an antagonistic effect on fire performances is observed: EPS with HBCD is downgraded from $\mathrm{E}$ to $\mathrm{F}$ rating.

\section{Acknowledgements}

We would like to thank members of the technical staff of C2MA: Kevin ROQUE for his help on the analysis of the polymer coating viscosity, Jean-Marie TAULEMESSE, for his contribution to the data interpretation of SEM and EDX results, Sylvain BUONOMO who contributed to the construction of the equipment for simulated fire test NF EN ISO 11925-2, Saint-Gobain Placo, that allowed implementing the standardized fire NF EN ISO 11925-2 on coated EPS containing HBCD, and also Saint-Gobain CREE, that supported this study.

\section{Appendix A. Supplementary data}

Supplementary data associated with this article can be found, in the online version, at http://dx.doi.org/10.1016/j.porgcoat.2016. 04.036.

\section{References}

[1] F. Asdrubali, F. D’Alessandro, S. Schiavoni, A review of unconventional sustainable building insulation materials, Sustainable Mater. Technol. 4 (2015) 1-17.

[2] M. Rossi, G. Camino, M. Ludab, Characterisation of smoke in expanded polystyrene combustion, Polym. Degrad. Stab. 74 (3) (2001) 507-512.

[3] HBCD use in EPS for Building Applications, ICL-IP Europe BV, 06/07/2014, http://echa.europa.eu/documents/10162/18074545/a4a_comment_569_1_ attachment_en.pdf, (available from 18/08/2015).

[4] J. Heibl, W. Vetter, Detection of hexabromocyclododecane and its metabolite pentabromocyclodedecane in chicken egg and fish from the official food control, J. Agric. Food Chem. 55 (2007) 3319-3324.

[5] A. Covaci, A.C. Gerecke, R.J. Law, S. Voorspoels, M. Kohler, N.V. Heeb, H. Leslie, C.R. Allchin, J. De Boer, Hexabromocyclododecanes (HBCDs) in the environment and humans: a review, Environm. Sci. Technol. 40 (12) (2006) 3679-3688.

[6] S.D. Shaw, A. Blum, R. Weber, K. Kannan, D. Rich, D. Lucas, C.P. Koshland, D. Dobraca, S. Hanson, L.S. Birnbaum, Halogenated flame retardants: do the fire safety benefits justify the risks? Rev. Environ. Health 25 (4 (Oct-Dec)) (2010) 261-305. 
[7] Commission Regulation (EU) No 143/2011 of 17 February 2011, Official Journal of the European Union, 18 February (2011).

[8] Maxwell K.A., Goossens D.K, Mack A., Flame Retardant Polystyrene Foam Compositions, July (2006), WO2006/071217A1.

[9] Chinomi R., Sakamoto K., Yamada K., Expandable polystyrene resin particles and process for producing same, February (2012), EP 2415826 A1.

[10] E.D. Weil, S.V. Levchik, Flame Retardants for Plastics and Textiles: Practical Applications, Hanser Publisher, Munich, 2009.

[11] Wolfgang M., Walter A., Flame-proof polystyrene foam and process for the manufacture thereof, April (1980), US 4198486.

[12] Li S., Flame-retarding polystyrene heat insulation material and preparation method thereof, CN102775690 (A).

[13] Eberstaller R., Hintermeier G., Flameproof expandable polymerizates, Oct (2012), US 20120264837 A1.

[14] Aslin D.C., Fire resistant materials, August (2010), US 7772294 B2.

[15] Hahn K., Stange K., Walter M., Weber H., Self-extinguishing, expandable styrene polymers, US 4218511 A, August (1980).

[16] Ingram A.R., Fire-resistant styrene polymer foams, July. 1977, US 4035315 A

[17] Brouwer W.D., Engelbertus Las E.H., Liemt W.V., Rauniyar G., Marie Souren W.H., Fire retardant polystyrene, May (2010), US 2010/0119813 A1.

[18] G. Camino, A. Maffezzoli, M. Braglia, M. De Lazzaro, M. Zammarano, Effect of hydroxides and hydroxycarbonate structures on fire retardant effectiveness and mechanical properties in ethylene-vinyl acetate copolymer, Polym. Degrad. Stab. 74 (2001) 457-464.

[19] R. El Hage, A. Viretto, R. Sonnier, L. Ferry, J.M. Lopez-Cuesta, Flame retardancy of ethylene vinyl acetate (EVA) using new aluminum-based fillers, Polym. Degrad. Stab. 108 (2014) 56-67.

[20] B. Schartel, K. Pawlowski, R. Lyon, Pyrolysis combustion flow calorimeter: a tool to assess flame retarded PC/ABS materials? Thermochim. Acta 462 (2007) $1-14$.

[21] B. Friederich, A. Laachachi, R. Sonnier, M. Ferriol, M. Cochez, V. Toniazzo, D. Ruch, Comparison of alumina and boehmite in (APP/MPP/metal oxide) ternary systems on thermal and fire-resistance properties of PMMA, Polym. Adv. Technol. 23 (2012) 1369-1380.
[22] G. Droval, I. Aranberri, J. Ballestero, M. Verelst, J. Dexpert-Ghys, Synthesis and characterization of thermoplastic composites filled with $\gamma$-boehmite for fire resistance, Fire Mater. 35 (2011) 491-504.

[23] L. Ferry, R. Sonnier, J.M. Lopez-Cuesta, S. Petigny, C. Bert, Thermal degradation and flammability of polyamide 11 filled with nanoboehmite, in: Sophie Duquesne, Serge Bourbigot (Eds.), Flame Retardancy and Protection of Materials: Recent Advances and Current Perspectives, Springer, 2016.

[24] J. Zhang, Q. Ji, P. Zhang, Y. Xia, Q. Kong, Thermal stability and flame-retardancy mechanism of poly(ethylene terephthalate) nanocomposites, Polym. Degrad. Stab. 95 (2010) 1211-1218.

[25] E. Guido, J. Alongi, C. Colleoni, A. Di Blasio, F. Carosio, M. Verelst, G. Malucelli, G. Rosace, Thermal stability and flame retardancy of polyester fabrics sol-gel treated in the presence of boehmite nanoparticles, Polym. Degrad. Stab. 98 (2013) 1609-1616.

[26] M. Monti, G. Camino, Thermal and combustion behavior of polyethersulfone-boehmite nanocomposites, Polym. Degrad. Stab. 98 (2013) 1838-1846.

[27] Y. Cai, M. Zhao, H. Wang, Y. Li, Z. Zhao, Syntheis and properties of flame-retardant poly(vinyl alcohol)/pseudo-boehmite nanocomposites with high transparency and enhanced refractive index, Polym. Degrad. Stab. 99 (2014) 53-60.

[28] Bert C., Hamdani-Devarennes S., El Hage R., Composition aqueuse ignifuge, September (2013), FR 3011245 A1.

[29] Bert C., Hamdani-Devarennes S., Polystyrène expansé ignifugé par hydroxyde d'aluminium, September (2013), FR 3011242 A1.

[30] Hamdani-Devarennes S. Bert C., Espiard P., Fabric comprising a transparent, fire-resistant coating, April (2015), WO 2015/044616 A1.

[31] M. Alkan, R. Benlikaya, Poly(vinyl alcohol) nanocomposites with sepiolite and heat-treated sepiolites, J. App Polym Sci 112 (2009) 3764-3774. 